\title{
WestVirginiaUniversity
}

THE RESEARCH REPOSITORY @ WVU

Graduate Theses, Dissertations, and Problem Reports

2016

\section{Psychosocial Predictors of Resilience in a Military Sample}

Anna-Marie C. Jaeschke

Follow this and additional works at: https://researchrepository.wvu.edu/etd

\section{Recommended Citation}

Jaeschke, Anna-Marie C., "Psychosocial Predictors of Resilience in a Military Sample" (2016). Graduate Theses, Dissertations, and Problem Reports. 5873.

https://researchrepository.wvu.edu/etd/5873

This Dissertation is protected by copyright and/or related rights. It has been brought to you by the The Research Repository @ WVU with permission from the rights-holder(s). You are free to use this Dissertation in any way that is permitted by the copyright and related rights legislation that applies to your use. For other uses you must obtain permission from the rights-holder(s) directly, unless additional rights are indicated by a Creative Commons license in the record and/ or on the work itself. This Dissertation has been accepted for inclusion in WVU Graduate Theses, Dissertations, and Problem Reports collection by an authorized administrator of The Research Repository @ WVU.

For more information, please contact researchrepository@mail.wvu.edu. 
Psychosocial Predictors of Resilience in a Military Sample

Anna-Marie C. Jaeschke, M.S., M.A.

Dissertation submitted to the College of Physical Activity and Sport Sciences at West Virginia University

in partial fulfillment of the requirements for the degree of

Doctor of Philosophy

In

Kinesiology

With an emphasis in Sport and Exercise Psychology

Peter Giacobbi Jr., Ph.D. (Committee Chair)

James Hannon, Ph.D.

Kristen Dieffenbach, Ph.D.

Christa Lilly, Ph.D.

Stephen Gonzalez, Ph.D.

College of Physical Activity and Sport Sciences

Morgantown, West Virginia

December 2016

Keywords: Coping Self-Efficacy, Military, Optimism, Physical Activity, Resilience 


\begin{abstract}
Predictors of resilience, specifically optimism, social support, coping self-efficacy, and physical activity were explored in a sample of United States Army Active Duty service members and Veterans $(N=302)$. The participants were a predominantly white $(86 \%)$ sample of 191 males and 111 females, age 19 to $74(M=39.94, S D=10.31)$. A cross-sectional survey design was used to identify predictors of resilience, examine differences in resilience based on demographic factors, and differences in resilience scores between those who had and had not completed resilience training. Regression analyses revealed that optimism and self-efficacy were significant predictors of resilience, $[F(5,287)=76.90, p=.00]$ and accounted for $57.7 \%$ of the variation in resilience, while controlling for gender, education, and participation in resilience training. Male participants reported statistically significantly higher resilience scores $(M=32.13, S D=6.31)$, than female participants $(M=30.11, S D=5.86), t(308)=2.78, p=.006)$, age was not a significant predictor, education had a slightly significant relationship with resilience $[\beta=0.20$, 95\% CI $(.40,1.41), t=3.52, p=.001]$. Participants who reported completing resilience training scored higher on resilience than those who reported not having completed the training. These findings carry strong support and additional considerations for existing resilience training efforts. The research supports the notion that resilience can be developed and this could happen through identifying paths to an optimistic mindset and supporting internal (visualization, meditation, problem-solving, self-talk) and external (unit support, recreational activities, friends and family) resources.
\end{abstract}




\section{Table of contents}

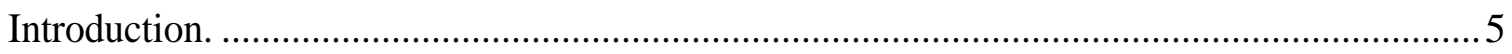

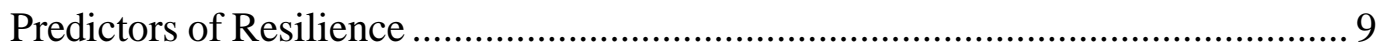

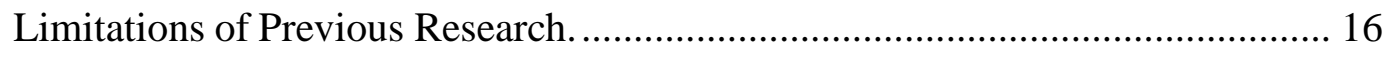

Rationale, Purpose, Hypotheses ....................................................................... 17

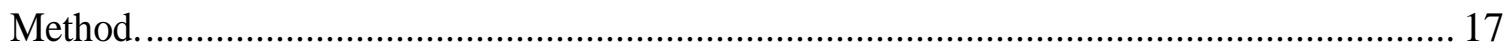

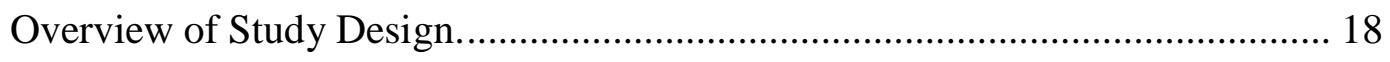

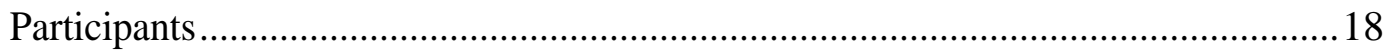

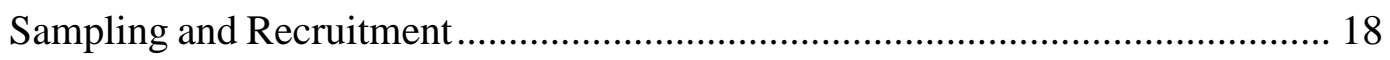

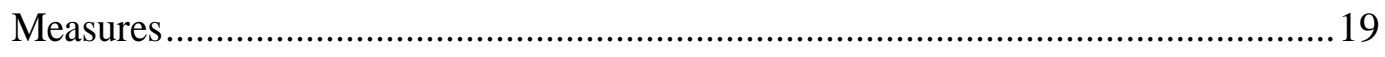

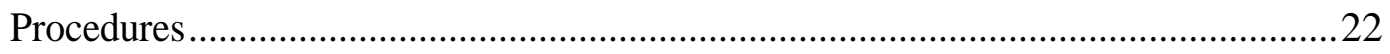

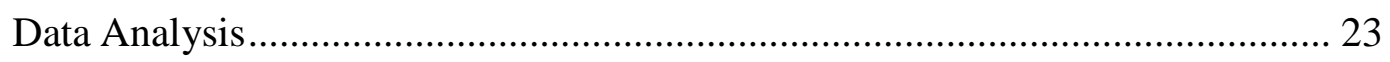

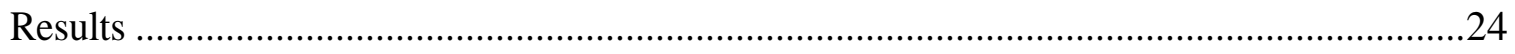

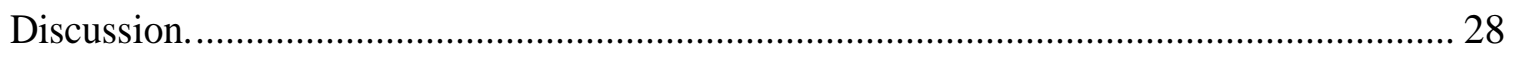

Limitations and Recommended Future Research..................................................36

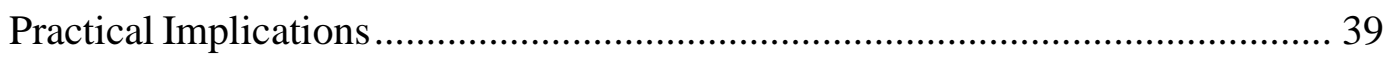

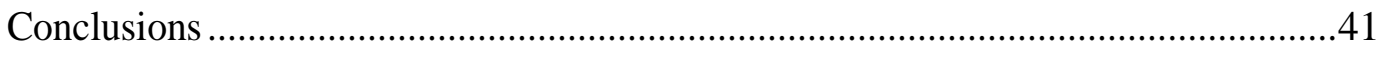

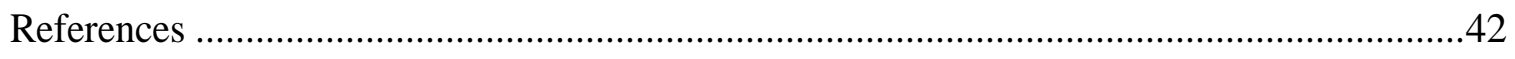

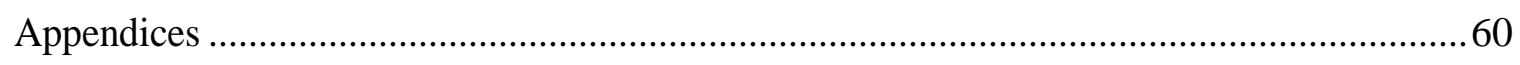

Appendix A: Recruitment advertisement and Informed consent .......................... 61

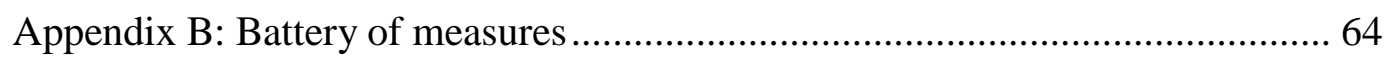

i. Demographic and military service questions ......................................... 65 
ii. Physical activity

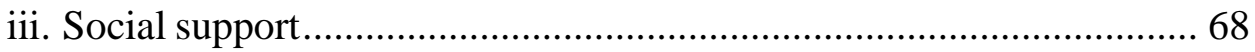

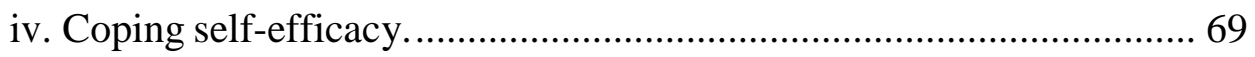

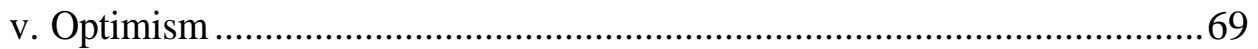

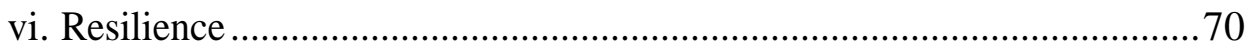

Appendix C: Resource page for all participants............................................. 71

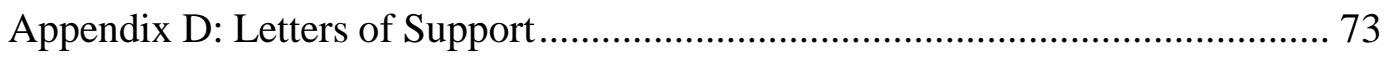

Appendix E: Expanded Literature Review .....................................................76 


\section{Introduction}

Extreme stress and adaptation to adversity are common for individuals serving in combat and non-combat military environments (Bowles \& Bates, 2010). Stressors can be caused by repeated deployments, interpersonal difficulties, combat exposure, transition following service, and lack of coping resources. Chronic stress, particularly within service-members, can lead to numerous physiological and psychological concerns, (Kaylor, King, \& King, 1987; Stanley, Schaldach, Kiyonaga, \& Jha, 2011) including disturbed sleep (Winwood \& Lushington, 2006), chronic pain (Beckham et al., 1997), PTSD, depression, and anxiety disorders (Adler, Vaitkus, \& Martin, 1996; Milliken, Auchterlonie, \& Hoge, 2007). Therefore, understanding ways to promote resilience, or the ability to bounce back in the face of adversity, and cultivate a greater ability to positively adapt to stress within military populations is an important undertaking.

The United States Army recognized that American soldiers were accumulating stress, specifically during Operation Iraqi Freedom (OIF; 2003-2011) and Operation Enduring Freedom (OEF; 2001-2012). The stress associated with these and possible multiple deployments can weigh on an individual's mental health, physical well-being, and interpersonal relationships (Griffith \& West, 2013; Meredith, Sherbourne, \& Gaillot, 2011). Resilience training programs, such as The Army's Comprehensive Soldier and Family Fitness Program (CSF2), have rapidly grown in the past several years within the military and other workplace contexts (Bowles \& Bates, 2010; Vanhove, Herian, Perez, Harms, \& Lester, 2015). The CSF2 program is a proactive approach to cultivating resilient traits in soldiers, family members, and civilian support staff for armed forces (Casey Jr, 2011; Harms, Herian, Krasikova, Vanhove, \& Lester, 2013). The program focuses on building personal and psychological strengths; the mission is to provide support so soldiers can be more mentally fit prior to deployment to combat. 
According to Army Regulation 350-53, as of June 2014, all enlisted soldiers must complete annual training of CSF2 Resilience and Performance Skills (Odierno, 2014). Resilience training programs have been supported through evaluations that identified positive mental and behavioral outcomes of soldiers who have completed resilience training (Harms et al., 2013). The CSF2 program consists of modules designed to address six core competencies: connection, optimism, mental agility, self-awareness, self-regulation, and character strength (Griffith \& West, 2013).

In one study, researchers used the Global Assessment Tool (GAT) to measure resilience and psychological health at multiple time points in a large sample of soldiers $(N=7230)$, some of which completed the resilience training through CSF2 $(n=4983)$, some of which had not $(n=$ 2247) (Peterson, Park, \& Castro, 2011). Mediation analyses revealed that resilience training was associated with increases in optimism, adaptability, coping, friendship, and character. Also, adaptability and optimism mediated the effects of the resilience training on mental health diagnoses. Another central finding was that the resilience training had a direct negative effect on substance abuse in the sample. The findings were congruent with the goal of the program to use a strength-based approach to indirectly reduce depression, anxiety, and PTSD symptomology (Reivich, Seligman, \& McBride, 2011a).

What follows is a review of conceptual, theoretical, and empirical literature pertinent to the study of resilience and related psycho-social constructs.

\section{Resilience}

Resilience is the ability to "bounce back" or rebound from stressful or adverse events and maintain a stable or even enhanced level of well-being and psychological health (Cornum, Matthews, \& Seligman, 2011; Reivich \& Shatte, 2002). Resilience has been defined in various 
ways depending on the social, cultural, and historical context within which it is defined, researcher perceptions, and characteristics of the sample population (Fletcher \& Sarkar, 2013; J. H. Lee et al., 2013; Meredith et al., 2011; Windle, 2011). However, two factors appear to be most salient: the presence of adversity and an adaptation response which could be a return to normal functioning or flourishing. Resilience has been defined in the military context as the culmination of psychological processes that allow individuals to maintain or return to existing levels of functioning and well-being following adversity (Crane et al., 2012). In the military, the adaptation response could manifest as post-traumatic growth or the adoption of resilience-related skills (Pietrzak \& Southwick, 2011).

It is vital to explore what predicts resilient traits in military populations due to the combined physical and psychological nature of military involvement and the need to positively adapt to stress in occupational and interpersonal situations. Resilience should also be explored both conceptually and operationally to be clear as to how it might be developed in a military population. Conceptually, resilience is rooted in developmental psychology as a construct built over time through experiences and adversity such as extreme poverty, trauma, and stress (Garmezy, 1991; Meredith et al., 2011). However, the culmination of chronic and acute stressors informs the need to operationally define resilience as a trait and a construct extending beyond an individual becoming resilient after a single event. Instead, resilience constitutes coping strategies that alleviate or even prevent detrimental emotional consequences of difficult experiences (Ano \& Vasconcelles, 2005). It is important to consider resilience as an interaction between dispositional aspects of one's personality (such as optimism), and responses to environmental cues (such as coping and social support) also in conjunction with adaptive behaviors (physical activity). Resilience is a multidimensional construct and while the situational component of 
stressful events may induce state-like coping, the adaptation response of resilience over time from adversity warrants a more general form of operational definition and measurement.

Military personnel encounter both acute and chronic stressors related to their service and in other aspects of their life, informing the need to examine protective factors related to resilience and clarify demographic differences that may inform resilience-oriented interventions.

\section{Demographic Considerations of Resilience}

The study of age and gender differences in resilience has received empirical attention with inconsistent findings. A meta-analytic method was used to uncover a large effect of protective factors (optimism, self-confidence, positive affect), a medium effect from risk factors (depression, PTSD), and the smallest effect from demographic factors such as age and gender as contributors to resilient qualities (J. H. Lee et al., 2013). Some studies found that as people age, they exhibit fewer resilient qualities (Beutel, Glaesmer, Decker, Fischbeck, \& Brähler, 2009; Lamond et al., 2008), while other studies found that consistent with theories of resilience increasing over life experiences with adversity, resilience scores increased with age (CampbellSills, Forde, \& Stein, 2009; Gillespie, Chaboyer, \& Wallis, 2009). Lastly, Connor and Davidson (2003) found no correlation between age and scores on the Connor-Davidson Resilience Scale (CD-RISC; Connor \& Davidson, 2003), the CD-RISC is not designed to measure resilience (which is a dynamic process), but rather the presence of resilient characteristics.

Additionally, researchers have proposed that there are significant differences in resilience scores between males and females. One meta-analysis found that across 60 international studies on trait resilience and mental health, females scored lower on resilience than males ( $\mathrm{Hu}$, Zhang, \& Wang, 2015). The authors speculated that these differences were due to different means of socialization, lower scores on self-efficacy and self-confidence measures, lower perceptions of 
support (Costa, Terracciano, \& McCrae, 2001), weaker senses of mastery, and a rumination style of coping (Nolen-Hoeksema, 1991). Other studies reported that females were more resilient than males (Davidson et al., 2005; McGloin \& Widom, 2001). The employment of small homogenous samples could have contributed to the mixed findings in these studies. It is clear that while the exploration of demographic characteristics in a military sample is beneficial, empirical support for most prominent contributors to resilience lies in protective factors, or predictors of resilience over demographic features.

\section{Predictors of Resilience}

Psycho-social correlates of resilience are also important for understanding this construct. Early studies of resilience focused on what factors contributed to positive adaptation and included factors such as self-efficacy, internal rather than external locus of control, humor (Rutter, 1985), optimism, and social support (Masten, Best, \& Garmezy, 1990) . More recent examinations of resilience describe the construct associated with a constellation of psychological characteristics including optimism (Lamond et al., 2008; H. Lee, Brown, Mitchell, \& Schiraldi, 2008; J. E. Lee, Sudom, \& McCreary, 2011; Min et al., 2013; Petros, Opacka-Juffry, \& Huber, 2013; Steinhardt \& Dolbier, 2008), coping self-efficacy (Benight \& Bandura, 2004; CampbellSills, Cohan, \& Stein, 2006; Cody, 2013; Hamill, 2003; Southwick, Litz, Charney, \& Friedman, 2011) social support (Benight, Swift, Sanger, Smith, \& Zeppelin, 1999; Hourani et al., 2012; Mummery, Schofield, \& Perry, 2004; Smith, Benight, \& Cieslak, 2013) and physical activity (Deuster \& Silverman, 2013; Hegberg \& Tone, 2015; Southwick \& Charney, 2012; Taylor et al., 2008). Empirical and theoretical justification for the study of these psychological and behavioral correlates of resilience will be explored in the following subsections. 
Optimism. Optimism has been defined as the extent to which individuals retain generally positive or favorable expectations for the future (Carver, Scheier, \& Segerstrom, 2010). In a cross-sectional study, researchers examined correlations between resilience and positive characteristics, depressive symptoms, trait anxiety, and early life stress (Petros et al., 2013). This non-clinical sample $(\mathrm{N}=196)$ completed a battery of psycho-social questionnaires to measure resilience, self-efficacy, optimism, anxiety, depression, well-being, social support, and early life stress. The researchers found strong positive correlations between resilience, optimism $(r=.61)$, and self-efficacy $(r=.78)$. It is suggested that optimism, or the anticipation of generally positive outcomes, may improve the opportunities for one to cope successfully.

Other researchers sought to assess how community-dwelling older women $(\mathrm{N}=1395)$ adapt to adversity and how this could be an important part of aging (Lamond et al., 2008). In an effort to explore psychometric aspects of the CD-RISC in a large sample of women over 60, the aim was to see if CD-RISC scores would correlate positively with aspects of successful aging, including cognitive functioning, social engagement, and optimism. The measures used included the CD-RISC (Connor \& Davidson, 2003), a self-rated scale of successful aging, number of days per week visiting with friends and family, a measurement of physical functioning, a measure of emotional health/well-being, two cognitive functioning tests, and lastly The Life Orientation Test (Scheier \& Carver, 1985). CD-RISC scores were positively correlated with education $(r=.06)$, emotional health/well-being $(r=.49)$, optimism $(r=.44)$, successful aging $(r=.43)$, social engagement $(r=.14)$, and physical functioning $(r=.12)$. In stepwise regression analysis with the positively correlated variables, the final model, which accounted for $38 \%$ of the variance in CDRISC scores, included emotional health/well-being, cognitive functioning, successful aging, optimism, and social engagement. 
Coping self-efficacy. Coping self-efficacy (CSE) is a specific form of self-efficacy and can be defined as one's perception of his or her capability to manage threatening or stressful demands of the environment (Benight et al., 1999). Research shows clear links between resilient characteristics and general self-efficacy (Connor \& Davidson, 2003; Hegberg \& Tone, 2015). However, the relationship between coping self-efficacy and resilience has not been systematically explored which is surprising given that coping self-efficacy has been identified as a critical mediator in post-traumatic recovery (Benight \& Bandura, 2004). Research and use of the Coping Self Efficacy Scale (Chesney, Neilands, Chambers, Taylor, \& Folkman, 2006) has been limited to acute instances of natural disasters, bombings, and motor vehicle accidents (Benight et al., 2000; Benight, Ruzek, \& Waldrep, 2008; Benight et al., 1999; Sumer, Karanci, Berument, \& Gunes, 2005) rather than continuous or ongoing circumstances that would require the development of coping skills.

A recent study explored whether coping self-efficacy, as an underlying mechanism of resilience, changed over time following a traumatic event (Waldrep, 2015). Participants included adults $(N=74)$ that had been admitted as hospital trauma in-patients, with traumas including but not limited to motor vehicle accidents, assault, gunshot wounds, serious fires, natural disasters, and military combat exposure. Participants filled out an instrument designed to measure coping self-efficacy by assessing the self-perceived ability of respondents to meet demands of coping after a traumatic event. Researchers also measured social support, posttraumatic stress symptoms, peritraumatic dissociation, and depressive symptoms. Coping self-efficacy (examined as an underlying component of resilience) presented a negative correlation with posttraumatic stress symptoms and peritraumatic dissociation, and a strong positive correlation with social support (Waldrep, 2015). 
In a meta-analysis examining 33 studies of resilience and psychological factors with 31,071 participants, researchers found that it was more effective to enhance protective factors such as coping self-efficacy and optimism to improve resilience rather than try to reduce risk factors such as anxiety and depression (J. H. Lee et al., 2013). The emphasis on the positive and adaptable qualities over identifying the illness of PTSD or symptoms of trauma exposure is a prominent theme in the field of positive psychology, which formed the foundation for both research and training in resilience (Seligman \& Csikszentmihalyi, 2000). Studies that extend beyond risk factors and explore positive social-cognitive mechanisms may influence critical outcomes such as resilience and post-traumatic growth (Benight \& Bandura, 2004). Social cognitive theory (SCT) helps build a framework for understanding the connection between social-cognitive constructs and environmental factors such as social support.

Social support. Social support can enhance functioning by facilitating the adaptation of effective coping strategies (Holahan, Moos, Holahan, \& Brennan, 1995). Studies focusing on external coping resources such as social support suggest that strong social bonds in Veterans can lead to lower PTSD symptomology (Charuvastra \& Cloitre, 2008; Tsai, Harpaz-Rotem, Pietrzak, \& Southwick, 2012). High perceptions of social support have been significantly correlated to higher resilience scores (Bonanno, 2004; Bonanno, Galea, Bucciarelli, \& Vlahov, 2007) . In both a longitudinal study of resilience (Hourani et al., 2012) and mental health and a crosssectional study of soldiers post-deployment (Cunningham et al., 2014), social support was cited as a critical piece of resilience and adjustment in soldiers as they transition out of service.

Hourani and colleagues (2012) examined both risk and protective factors in Marines who had been exposed to combat and were participating in a transition assistance program. Data were collected while the participants were in the workshop and again at a six-month follow-up into 
their civilian life $(N=475)$. Researchers measured resilient characteristics using the CD-RISC (Connor \& Davidson, 2003), social support using the Multidimensional Scale of Perceived Social Support (Zimet, Dahlem, Zimet, \& Farley, 1988), along with measuring stressors, life events, physical health problems, overall stress index, number of pain sites, previous trauma, risk taking, and health behaviors (physical activity and smoking). Social support and resilience were statistically and significantly correlated, even though the relationship was weak $(r=.17, p<.01)$. Within the four mental health outcomes, controlling for other variables in the model, the most significant variables were gender, pre-separation combat exposure, resilience, number of pain sites, stress, and social support at follow up. Additionally, those who scored high on social support at follow up were 5.3 times more likely to have improved from baseline to the six month follow up on self-reported mental health symptoms (Hourani et al., 2012).

In another study, researchers sought to identify the role of resilience, social support, exposure to combat, stressful deployment environments, and life stress in predicting postdeployment adjustment (Cunningham et al., 2014). A relatively healthy sample of Navy service members $(N=128)$ completed measures for post-deployment adjustment, resilience, postdeployment social support, deployment environment, combat exposure, and life events. A central hypothesis was that service members with low exposure to combat, stressful deployment environments, and additional life stress and high in social support and resilience would have better adjustment post-deployment. Even after controlling for covariates (gender, marital status, number of land-based deployments, MOS, IA experience, and perceived threat while deployed), the results of a logistic regression revealed that post-deployment social support and resilience were significant predictors of adjustment (Cunningham et al., 2014). Pietrzak and colleagues (2010) supported this by finding a full mediation effect of resilience in the relationship between 
unit support and PTSD, supporting the strong positive association between social support and resilience (Bonanno, Galea, Bucciarelli, \& Vlahov, 2007; Pietrzak et al., 2010).

Physical activity. Physical fitness is a vital component of military training and ongoing service through regular fitness testing. Additionally, the psychological and physical benefits of regular physical activity are well-documented in the literature and can specifically buffer the stressful effects of transition and exposure to trauma (Gerber \& Pühse, 2009; Hegberg \& Tone, 2015; Roth, Wiebe, Fillingim, \& Shay, 1989). Physical fitness and regular exercise can contribute to the development of resilient qualities by buffering physical and psychosocial stress reactivity, protecting against chronic illness and stress disorders, and providing multiple physiologic, psychological, and social benefits (Deuster \& Silverman, 2013). Literature on exercise and stress revealed that regular physical activity contributes to lower risks for developing stress-related mental and physical health issues (Gerber \& Pühse, 2009; Hegberg \& Tone, 2015).

In an examination of college students $(n=222)$, researchers examined if the association between physical activity and stress resilience was moderated by trait anxiety (Hegberg \& Tone, 2015). The Connor Davidson Resilience Scale 10 (Campbell-Sills \& Stein, 2007), was used in conjunction with a global physical activity questionnaire and a measure for trait anxiety. Hierarchical linear regression analyses revealed that anxiety significantly moderated the association between resilience and physical activity, after controlling for age, gender, and race. Across all levels of trait anxiety, there was evidence that those who reported high recreational physical activity also scored higher in self-perceived resilience, with the most significant trend for the association between physical activity and resilience in the individuals with high trait anxiety $(\beta=.063, t[215], p=.001)$. 
In addition to physical activity, physical fitness has been suggested as having a powerful role in attenuating stress reactions in the military and even buffering the effects of PTSD due to the relationship between physical fitness and stress reactivity (Crews \& Landers, 1987). Researchers examined whether physical fitness had an impact on participants $(N=31)$ responses to stressful events during a Survival, Evasion, Resistance, and Escape (SERE) training (Taylor et al., 2008). Physical fitness was measured using the most recent Physical Readiness Test (pushups, sit-ups, and run), along with measurements of trait anxiety and a measure of current subjective distress surrounding a life event. Physical fitness was inversely related with scores on the Impact of Events Scale (Horowitz, Wilner, \& Alvarez, 1979) when measured 24 hours after SERE training. It was demonstrated that aerobic fitness may buffer stress symptoms associated with highly stressful situations in military contexts, additionally these effects may be mediated by a relationship between fitness and reductions in trait anxiety (Taylor et al., 2008).

In summary, the psychosocial factors optimism, coping self-efficacy, and social support play a major role in contributing to overall resilience through various mechanisms. To date, no studies have explored all of these constructs simultaneously, particularly while also examining self-reported physical activity behavior. Both physical activity and social support can help buffer the effects of stress and enhance one's ability to recover from stressful situations (Deuster \& Silverman, 2013; Holahan et al., 1995). Optimism and self-efficacy have been repeatedly cited in the literature as playing a major role in the development of one's resilience (Segovia, Moore, Linnville, Hoyt, \& Hain, 2012). Additionally, resilience training emphasizes the benefits of changing one's belief or cognitive appraisal of stressors to reduce negative behavioral and emotional responses (Griffith \& West, 2013), thus comparing groups who have or have not received resilience training on these predictors would be beneficial. 


\section{Limitations of Previous Research}

As individual constructs, research has been conducted with military service members' physical activity (Baecke, Burema, \& Frijters, 1982; Boermans, Delahaij, Korteling, \& Euwema, 2012; Deuster \& Silverman, 2013; Taylor et al., 2008), optimism (Boermans et al., 2012; Griffith \& West, 2013; Thomas, Britt, Odle-Dusseau, \& Bliese, 2011) social support (Cunningham et al., 2014; Pietrzak et al., 2010; Smith et al., 2013; Tsai et al., 2012) and self-efficacy (Ginzburg, Solomon, Dekel, \& Neria, 2003; Pietrzak \& Southwick, 2011; Smith et al., 2013; Solomon, Benbenishty, \& Mikulincer, 1991). However, research has not collectively linked these factors together as predictors of resilient attributes, and exploration has not been done on what relative contributions these protective factors make within a sample of military service members and Veterans resilience qualities or characteristics.

Additionally, resilience has been explored extensively within Active Duty personnel (Griffith \& West, 2013; Hourani et al., 2012; Reivich et al., 2011a; Reivich, Seligman, \& McBride, 2011b), and Veterans (Anestis, Khazem, Mohn, \& Green, 2015; Green, Calhoun, Dennis, \& Beckham, 2010; Hendricks Thomas, Plummer Taylor, Hamner, Glazer, \& Kaufman, 2015; King, King, Fairbank, Keane, \& Adams, 1998; Pietrzak \& Cook, 2013). However, resilience has not been explored comprehensively with both Active Duty service members and Veterans to see which psychosocial predictors might play the most vital role for the development of resilient qualities. Furthermore, research on resilience training programs have supported their efficacy, but there is a lack of identifying differences in resilience scale scores between those who have versus those who have not received resilience training.

\section{Rationale and Purpose}


In the military, resilience has evolved into a central concept in the development of preventative measures that facilitate soldier's management of military demands and stressors. An understanding of what contributes to a soldiers' ability to cope with multiple deployments or a Veterans' re-acclimation to civilian life can be vital for positive physical and psychological health outcomes. Evaluation of resilience training programs have revealed measurable increases in resilience and psychological health and lower rates of reported diagnoses of mental health issues (Harms et al., 2013). As individual constructs, coping self-efficacy, social support, and optimism along with physical activity contribute to overall resilience. It is also possible that age and gender differences exist when examining resilience in this sample. Assessing these variables may allow the identification of which constructs predict the most variance in resilience and help determine whether there are sub-group differences in resilience.

The purpose of this study was to assess psychological predictors of resilience among Veterans and Active Duty military personnel. More specifically, the researchers explored how coping self-efficacy, optimism, social support and physical activity predict variations in resilience. A secondary purpose was to explore differences between those who have or have not participated in a resilience training program. Finally, exploratory analyses were conducted to assess if resilience scores varied based on demographic variables (e.g. age and gender).

\section{Hypotheses}

It was hypothesized that social support, coping self-efficacy, optimism, and physical activity would be statistically significant predictors of resilience in this sample. It was also hypothesized that resilience scores would be significantly higher in those who self-report as receiving the resilience training compared to those who have not.

\section{Method}




\section{Overview of Study Design}

This study was a survey-based cross-sectional survey design with measures administered on a secure website using the Qualtrics research software system. Qualtrics is compatible with any internet browser and all data were stored on secure server. The study was approved by the West Virginia University Institutional Review Board in May 2016 (Protocol \#: 1605104858).

\section{Participants}

The target sample included any Active Duty (including Reserves and National Guard) and Veteran service members of the United States Army. The Department of Defense registers a total of 1,326,273 Active Duty service members across multiple branches, 504,330 of which are active within the US Army (Military One Source, 2014). It is documented that there are approximately 4.2 enlisted personnel per officer in the Army. Women represent $15.1 \%$ of the Active Duty force, and $31.2 \%$ of Active Duty service members identify themselves as a racial minority. The average age for Active Duty officers is 34.8 years, and the average age for enlisted personnel is 27.3 years. Compared to 1995 , more Active Duty service members are obtaining bachelors' degrees. Lastly, over half of all Active Duty military members are married (55.3\%), which is down from 1995. The projected Veteran population is over 21 million, with approximately $91 \%$ males and $9 \%$ females who have served in various branches of the military (Military One Source, 2014).

The goal was for the sample to represent as closely as possible, the larger military service member population, however this was limited by sampling constraints and included only those with regular internet access. Additionally, individuals were excluded if they self-identified as having serious mental illness.

\section{Sampling and Recruitment}


The sample was recruited through both convenience and snowball sampling measures by contacting several university Veteran support groups, social media, outreach through Veteran/military support programs such as Team Red, White, and Blue (non-profit organization that engages Veterans in local community activities), and local Veteran support centers. Snowball sampling was employed by asking all participants to continue to forward the link to those who fit the inclusion criteria.

The inclusion of both Active Duty and Veteran service members was to explore associations between years of service and resilience. The researcher understands that the military-related mandated physical activity will vary vastly within the group but felt it was important to explore a diverse range of military experiences. Additionally, few studies have included large diverse samples of individuals with varying types and lengths of military experience (Anestis et al., 2015).

\section{Measures}

All measures can be seen in Appendix B. Participants were sent a link to a questionnaire via email or social media inquiring about their age (in years), sex, marital status, race, ethnicity, level of education, and geographic location. Participants were also asked if they were enlisted, an officer, or warrant officer during their service, the duration of their service (in years and months), and if they self-identify as Active Duty or as a Veteran. Finally, the demographic measure included a question about whether participants have ever completed a formal resilience-training program, and if they had participated in resilience training, if they found it useful.

Resilience. The CD-RISC was used to assess the dependent variable of resilience (Connor \& Davidson, 2003). The CD-RISC is a 25-item scale that measures qualities of resilient people. The scale was developed from research in hardiness (Kobasa, 1979); action orientation, 
adaptability, and efficacy (Rutter, 1985), patience and stress endurance (Lyons, 1991), and optimism and faith (Alexander, 1998). The present study used the 10-item CD-RISC which comprises items $1,4,6,7,8,11,14,16,17$, and 19 from the original scale. It is scored out of 40 instead of out of 100 as with the CD-RISC 25. In a community-based survey of 764 adults administered the CD-RISC, mean scores were 31.80 (SD = 5.41) (Campbell-Sills et al., 2009). Responses to questions range along a five-point scale: (4) true nearly all the time, (3) often true, (2) sometimes true, (1) rarely true, and (0) not true at all. The instructions ask participants to indicate how much they agree with the statements over the last month. Scoring is a range from 0 to 40, with higher scores indicative of higher resilience (Connor \& Davidson, 2003). Sample questions include: "I tend to bounce back after illness, injury, or other hardships," and "I think of myself as a strong person when dealing with life's challenges and difficulties." Cronbach's alpha for the scale using the current sample was .90, indicating good internal consistency.

Optimism. The Life Orientation Test (LOT-R; (Scheier \& Carver, 1985) was used to assess dispositional optimism and pessimism. This measure consists of 10 items rated on a fivepoint Likert-type scale ranging from 0 "strongly disagree" to 4 "strongly agree," and it consists of three each positively and negatively worded statements (reverse scoring for the negatively worded statements), and four filler items. Sample questions include "In uncertain times, I usually expect the best" and "I'm always optimistic about my future." Using only the three optimism questions and exclusion the filler questions, participants can score anywhere from 0 to 14 , with a higher score indicative of higher dispositional optimism. Cronbach's alpha for the scale in the current sample was .76, indicating an acceptable level of reliability.

Coping self-efficacy. The Coping Self-Efficacy Scale (CSE; Chesney et al. (2006) is a 26-item measure designed to assess one confidence in exhibiting coping behaviors in the face of 
life challenges. The scale uses an 11-point Likert-type rating, with item responses scored from 0 to 10 , with 0 "cannot do at all" and 10 "certainly can do." Total scores can range from 0 to 260 in response to these statements. Sample statements include "make a plan of action and follow it when confronted with a problem" and "get emotional support from friends and family." This measure demonstrated strong reliability with the current sample $\alpha=.97$.

Social support. The Multidimensional Scale of Perceived Social Support (MSPSS; (Zimet et al., 1988) is a 12-item measure using a 7-point Likert-type scale ranging from 1 "very strongly disagree to 7 "very strongly agree," with higher ratings indicating stronger perceptions of social support. Three subscales were identified by Zimet et al. (1988) and found to have strong factorial validity. The three subscales measure (a) Family, (b) Friends, and (c) Significant Other; a principal components factor analysis confirmed the three 4-item subscale groupings for the 12items. Sample statements include "There is a special person with whom I can share my joys and sorrows," "I can talk about my problems with my family," and "My friends really try to help me." For the present study, this measure indicated strong reliability $\alpha=.77$.

Physical activity. A continuous outcome measure was used to assess vigorous, moderate, and light physical activity using the framework adapted from previously validated self-report measures of physical activity (Blair, 1984; Grzywacz \& Marks, 2001; Kohl, Blair, Paffenbarger, Macera, \& Kronenfeld, 1988; Washburn, Goldfield, Smith, \& McKinlay, 1990). This measure provides an estimated metabolic expenditure (MET) and accounts for seasonal variations in light, moderate, and vigorous physical activity. with the additional consideration for season. Grzywacz and Marks (2001) only assessed vigorous physical activity but the existing scale (ranging from 6 "several time a week or more" to 1 "never") in conjunction with assessing winter and summer ranges was also used to identify light and moderate physical activity as was included in a 
previously validated measure (Paffenbarger Jr, Blair, Lee, \& Hyde, 1993). Participants are provided with a description and example of each of the intensity levels of physical activity, which can then be used to calculate an average MET score (Strohacker, Wing, \& McCaffery, 2013).

\section{Procedures}

The researchers first obtained approval from the West Virginia University Institutional Review Board then reached out to several Active Duty military and Veteran contacts previously described. Individuals were sent a brief advertisement (see Appendix A) for the study and a link to Qualtrics to participate. In some cases, participants accessed the survey via the link sent out by a military contact person (see Appendix D for letters of support), on their own through the postings on social media sites for soldier and Veteran support organizations, or through other participants or contacts forwarding the survey link. Outreach contacts included professors of military science, Team Red White and Blue, a local Vet Center, and military colleagues of the researcher. The researchers employed convenience and snowball sampling to recruit eligible Active Duty service members and Veterans.

Prior to distribution of the survey to participants, the battery of surveys was pilot tested on three individuals in the military (two Active Duty, one Veteran) to check for flow of questions, layout, wording of instructions, and to assess how long the survey may take the participants. Each participant clicked to a secure link and his or her responses were recorded anonymously to each question with no identifying information. The survey opened with a cover letter (Appendix A) which clarified the research purpose and inclusion/exclusion criteria for participation along with informed consent. The battery of measures (Appendix B) took participants approximately five to ten minutes to complete. The final page of the survey was a 
list of support services and resources (Appendix C) and thank you to the participant for their time. The survey was open from July $29^{\text {th }}, 2016$ to August $11^{\text {th }}, 2016$ or approximately six weeks, until a sample size of 432 was reached.

\section{Data Analysis}

Scoring of all measures were conducted in line with the authors' recommendations. An apriori power analysis was performed using $\mathrm{G}^{*}$ Power Statistical Software 3.1 Performing this analysis revealed an approximate sample size of 448 . This was a one-tailed test because the researchers predicted there will be a difference between those who have versus those who have not received resilience training, and we anticipated the group that has received training to have higher overall resilience.

The first step of data analysis was data cleaning to decide how to manage missing data. For the regressions, missing data were evaluated using the option of excluding cases pairwise; therefore, participants with a missing variable were excluded from the regression.

Descriptive statistics for all measures along with tests for normality were calculated. Bivariate correlations were computed to examine the relationships between all study variables. T-tests were utilized to examine resilience scores in those who did or did not receive resilience training. Multiple regression analyses were used to explore the relationship between resilience and each predictor (optimism, coping self-efficacy, social support, and physical activity), while controlling for demographic variables as covariates. Assumptions of normality for multiple linear regression/logistic regression include sample size, multicollinearity, outliers, and linearity of outcome variables with predictor variables.

Normality of resilience was evaluated visually, using the Kolmogorov-Smirnov test, and Z-scores for both skewness and kurtosis. The histogram presented a normal curve and the Q-Q 
plot appeared normal. Levene's test was used to check for homogeneity of variance; resilience had a nonsignificant $(p=.493)$ probability value on the Levene's test, supporting adequate homogeneity of variance for resilience.

Prior to conducting a hierarchical multiple regression, assumptions of regression were tested. First, a sample size of 280 was regarded as sufficient given four independent variables (optimism, coping self-efficacy, social support and physical activity) along with covariates (gender, marital status, and education). Singularity was met due to the independent variables not being a combination of other independent variables. In an examination of the correlation matrix (Table 2), the only independent variables that were highly correlated were optimism and coping. However, the collinearity statistics (Tolerance and VIF) were within acceptable limits and thus the assumption of multicollinearity appears to have been met. Residual and scatter plots indicated the assumptions of normality, linearity, and homoscedasticity were all satisfied.

\section{Results}

Participants included males $(n=191)$ and females $(n=111)$, age 19 to $74(M=39.94, S D=$ 10.31). Most participants were white (86\%), married (60.6\%), and educated $(27.8 \%$ had received masters degrees). The sample reported service ranging 1.5 to 42 years. Most participants reported their service status as Enlisted (69.3\%), with the remainder of participants serving/had served as Officers (27.9\%) or Warrant Officers $(2.6 \%) 66.9 \%$ of the participants reported completing resilience training; of those, $65.5 \%$ described the training as useful. The sample include Active Duty service members (57.9\%) (including National Guard and Reservists), and Veterans (42.1\%). Table 1 characterizes the sample based on those who completed the resilience measure; the total number of participants who completed at least one survey item was 432 , the researchers used pairwise deletion to characterize the sample and run the main analyses. 
Table 1

Demographic Characteristics of the Study Sample

\begin{tabular}{|c|c|c|}
\hline Variable & $\mathrm{N}$ & $\mathrm{M}(\mathrm{SD})$ \\
\hline Age & 265 & $39.94(10.31)$ \\
\hline Duration of Service & 225 & $12.42(7.76)$ \\
\hline Variable & $\mathrm{N}$ & Percentage \\
\hline \multicolumn{3}{|l|}{ Sex } \\
\hline Male & 191 & 63.2 \\
\hline Female & 111 & 36.8 \\
\hline \multicolumn{3}{|l|}{ Marital Status } \\
\hline Single & 32 & 10.6 \\
\hline Committed Relationship & 26 & 8.6 \\
\hline Married & 183 & 60.6 \\
\hline Separated & 4 & 1.3 \\
\hline Divorced & 38 & 12.6 \\
\hline Divorced and Remarried & 16 & 5.3 \\
\hline Widowed & 3 & 1 \\
\hline \multicolumn{3}{|l|}{ Race } \\
\hline African American & 12 & 4.0 \\
\hline $\begin{array}{l}\text { American Indian/ } \\
\text { Alaskan Native }\end{array}$ & 2 & 0.7 \\
\hline Asian & 6 & 2 \\
\hline Biracial & 8 & 2.6 \\
\hline Caucasian & 258 & 86.0 \\
\hline Native Hawaiian & 1 & 0.3 \\
\hline Other & 14 & 4.7 \\
\hline \multicolumn{3}{|l|}{ Ethnicity } \\
\hline Hispanic/Latino & 25 & 8.3 \\
\hline Not Hispanic/Latino & 274 & 90.7 \\
\hline \multicolumn{3}{|l|}{ Education } \\
\hline High School & 13 & 4.3 \\
\hline $\begin{array}{l}\text { Some Undergraduate/ } \\
\text { Pursuing Degree }\end{array}$ & 78 & 25.8 \\
\hline Bachelors & 82 & 27.2 \\
\hline $\begin{array}{l}\text { Some Graduate/ } \\
\text { Pursuing Degree }\end{array}$ & 33 & 10.9 \\
\hline Masters & 84 & 27.8 \\
\hline Professional/Doctorate & 15 & 4.0 \\
\hline \multicolumn{3}{|l|}{ Geographic Location } \\
\hline Northeast & 47 & 15.6 \\
\hline
\end{tabular}




$\begin{array}{lcc}\text { Midwest } & 48 & 15.9 \\ \text { South } & 168 & 55.6 \\ \text { West } & 37 & 12.3 \\ \text { Other/International } & 2 & .7 \\ \text { Enlisted } & & \\ \text { Officer } & 194 & 69.3 \\ \text { Warrant Officer } & 78 & 27.9 \\ \end{array}$

Mean, standard deviations, and correlations for the predictor and outcome variables are presented in Table 2. Coping self-efficacy, optimism, and social support were all correlated with resilience $(p<.01)$. Physical activity was not significantly correlated.

First, t-tests were run to look at gender differences and compare Active Duty service members and Veterans. Male participants reported higher resilience scores $(M=32.13, S D=$ 6.31), than female participants $(M=30.11, S D=5.86), t(308)=2.78, p=.006)$. The effect size $(d=.36)$ indicated a small to medium effect using Cohen's standard for assessing effect sizes (Cohen, 1977). The overall mean of scores on the resilience scale were higher in Active Duty service members $(M=31.95, S D=6.13)$ compared to Veterans $(M=30.60, S D=6.27), t(307)=$ $1.88, p=.061$. The effect size was small $(d=.21)$. Although differences in mean scores were observed between the two groups, they were not statistically significant differences.

Table 2

Correlation Coefficients for Variables Included in the Study

\begin{tabular}{lcccccccc}
\hline Measure & 1 & 2 & 3 & 4 & 5 & 6 & 7 & 8 \\
\hline 1. Resilience & - & & & & & & & \\
2. Coping Self-Efficacy & $.74^{* *}$ & - & & & & & & \\
3. Optimism & $.63^{* *}$ & $.70^{* *}$ & - & & & & & \\
4. Overall Social Support & $.38^{* *}$ & $.53^{* *}$ & $.48^{* *}$ & - & & & & \\
5. Family SS & $.31^{* *}$ & $.43^{* *}$ & $.42^{* *}$ & $.884^{* *}$ & - & & & \\
6. Friend SS & $.41^{* *}$ & $.57^{* *}$ & $.47 * *$ & $.854^{* *}$ & $.65^{* *}$ & - & & \\
7. Sig. Other SS & $.27^{* *}$ & $.40^{* *}$ & $.37 * *$ & $.874^{* *}$ & $.64 * *$ & $.603 * *$ & - & \\
8. Physical Activity & 0.06 & $.16^{* *}$ & 0.11 & $.12^{*}$ & 0.11 & 0.09 & $.13^{*}$ & -
\end{tabular}




\begin{tabular}{lcccccccc}
$M$ & 31.38 & 185.69 & 11.17 & 65.17 & 21.53 & 21.17 & 22.54 & 507.96 \\
$S D$ & 6.22 & 48.64 & 2.48 & 16.57 & 6.54 & 9.94 & 6.57 & 93.18 \\
\hline
\end{tabular}

$* p<.05, * * p<.01$.

A linear regression was used to further examine the difference in resilience scores between those who did and did not participate in resilience training and found that only $2 \%$ of the variance in resilience scores were explained by participation in resilience training, $F(7,271)$ $=3.98, p=.000)$. For those who participated in training, their predicted resilience score would be 2.03 points higher than those who did not participate in training $[\beta=-2.03,95 \% \mathrm{CI}(-3.66,-.39)$, $t=-2.44, p=.015]$ while controlling for gender, marital status, and education.

A two stage hierarchical regression was conducted to examine predictors of resilience while controlling for gender, marital status, education, and resilience training. Demographic variables were entered in the first stage to examine their relative contribution. The predictors, optimism, coping self-efficacy, social support, and physical activity were entered in the second stage. The hierarchical regression revealed that only gender, education, and resilience training emerged as significant and contributed to $9.4 \%$ of variance in resilience scores, $F(4,284)=$ $7.25, p=.000$. The introduction of the predictor variables (optimism, coping self-efficacy, social support, and physical activity) explained an additional $57.9 \%$ of variation in resilience and this change in $R^{2}$ was significant, $F(8,284)=49.89, p=.000$.

The researchers used backward selection to create a more parsimonious model to explain the strongest predictors of resilience scores. The covariates included were: gender, education and completion of resilience training, along with two predictors: coping self-efficacy and optimism (Table 3). This regression revealed that coping self-efficacy and optimism were significant predictors of resilience, $[F(5,287)=76.90, p=.00]$ and accounted for $57.7 \%$ of the variation in resilience. The model addressed both demographic and psychosocial variables in relation to 
resilience. For each unit increase in coping self-efficacy, resilience increased by $0.57[\beta=0.57$, $95 \% \mathrm{CI}(.06,0.09), t=10.31, p=.00]$, while controlling for gender, education, and completion of resilience training. For each unit increase in optimism, resilience increased by $.22[\beta=.22,95 \%$ $\mathrm{CI}(.06, .86), t=10.39, p=.00]$, while controlling for gender, education, and completion of resilience training.

Table 3

Hierarchical Regression Predicting Resilience from Optimism and Coping Self Efficacy, While Controlling for Gender, Education, and Participation in Resilience Training $(N=287)$

\begin{tabular}{ccccccc}
\hline Predictor & & $\mathrm{R}^{2}$ & $\Delta R^{2}$ & $\beta$ & $t$ & Sig. $(p)$ \\
\hline Step 1 & Gender (Male) & 0.08 & 0.08 & & & \\
& Education & & & -0.17 & -2.87 & 0.004 \\
& Resilience Training & & & 0.20 & 3.52 & 0.001 \\
& (Y/N) & & & -0.14 & -2.43 & 0.016 \\
Step 2 & Optimism & 0.58 & 0.49 & & & \\
& CSE & & & 0.22 & 3.93 & 0.000 \\
& & & 0.58 & 0.57 & 10.31 & 0.000 \\
Total $R^{2}$ & $* p<.05, * * p<.01$ & & & &
\end{tabular}

\section{Discussion}

The purpose of this exploratory study was to examine predictors of resilience in a military sample of Active Duty and Veteran service members of the United States Army. A cross-sectional study design was used to investigate psychosocial and demographic predictors of resilience. The researchers also examined variations in resilience scores between those who selfreportedly had or had not received formal resilience training. In a sample (N=432) of adults who completed the survey, optimism, coping self-efficacy, social support, and physical activity were evaluated for their contributions to overall resilience scores. 


\section{Research Question 1}

The first research question examined the contribution of predictors to resilience, the researchers hypothesized that social support, optimism, coping self-efficacy, and physical activity would contribute to variance in resilience. However, only optimism and coping selfefficacy proved to be statistically significant predictors. Physical activity was neither correlated with nor a significant predictor of resilience. Social support was correlated with resilience but was not a significant predictor in the regression model. Optimism was the largest predictor and strongest positively correlated with resilience. This finding is consistent in multiple studies examining optimism and resilience (Lamond et al., 2008; H. Lee et al., 2008; Luthans, Avolio, Avey, \& Norman, 2007; Segovia et al., 2012). In one longitudinal study in which resilience was defined as the absence of a psychiatric diagnosis over a 37-year follow-up period, dispositional optimism accounted for $14 \%$ of the variance in resilience (Segovia et al., 2012), compared to optimism accounting for almost $25 \%$ of the variance in resilience in the present study.

Contrary to finding that optimism contributed more to resilience than self-efficacy, a meta-analysis of resilience and protective factors found that self-efficacy emerged as the strongest variable related to resilience, even stronger than life satisfaction, optimism, positive affect, social support, and self-esteem (J. H. Lee et al., 2013). In the meta-analysis overall, the protective factors emerged as having a stronger positive impact on resilience than the weaker negative correlation of risk factors (anxiety, depression, negative affect, stress, PTSD) to resilience. This bolsters the findings from the present study support the focus on protective factors rather than risk factors (such as combat stress, depression, marital problems etc.) when informing the building blocks of resilience (J. H. Lee et al., 2013). 
Coping self-efficacy also contributed to significant variance in resilience, also in agreement with the research hypothesis and several previous studies linking coping and resilience (Tsai et al., 2012), and coping self-efficacy specifically with resilience to distress (Benight et al., 2000; Benight et al., 1999; Smith et al., 2013). One study evaluated social support and post-deployment coping self-efficacy in a sample of both active duty and Veteran service members who had served in combat situations. Through a mediation analysis, the researchers found that social support indirectly predicted distress severity by working through post-deployment coping self-efficacy (Smith et al., 2013). It was emphasized that perceptions of social support contributed to healthier adaptation post-deployment through improving individual's perceptions of self-efficacy. Interventions focused on self-efficacy were mentioned as potential avenues to reduce distress, increase resilience, and improve one's ability to access internal (confidence) and external (social support) resources.

Another study examined coping self-efficacy as a mediator of distress after a Hurricane (Benight et al., 2000). While social networks affected by a disaster experience similar challenges and can be supportive of one another, the case is different with combat Veterans and other military personnel since their support networks outside of the service have difficulty understanding the challenges associated with going to war (Smith et al., 2013). In another study, optimism partially mediated the relationship between self-efficacy and perceived social support to well-being (Karademas, 2006). Using similar variables as the present study, it would be beneficial for future researchers to run mediational analyses on a military sample to see how coping self-efficacy, optimism, and social support might interact in relation to resilience.

Multiple factors could have contributed to optimism and coping self-efficacy presenting as the highest predictors of resilience. Additionally, $67.4 \%$ of the participants reported that they 
had received resilience training, optimism is cited as one of the six MRT core competencies in the resilience training program (Harms et al., 2013). The participants' completion of resilience training might have exposed them to avenues to support their optimism or have a generally more favorable outlook. In an evaluation of outcomes from the Comprehensive Soldier and Family Fitness Program, optimism emerged as a mediator between the effects of resilience training on diagnoses for mental health problems (Harms et al., 2013).

Consistent with hypotheses, coping self-efficacy and optimism were found to be strong predictors of resilience; while social support was correlated with resilience, it was not found to be a significant predictor when controlling for other covariates. In a longitudinal study of resilience and mental health, researchers also used the Multidimensional Scale of Perceived Social Support (Zimet et al., 1988) and the CD-RISC (Connor \& Davidson, 2003) to measure resilience. The researchers found a strong positive correlation between resilience and social support $(r=.17)$, which was not as strong as in the present study $(r=.38)$. Social support emerged as one of the strongest protective factors of resilience that was associated with improvement in mental health over time (Hourani et al., 2012). These findings highlight the importance of implementing "transition buddies" or other social relationships to ease the transition process from service to civilian life (Hourani et al., 2012).

In other studies examining resilience, and more military-specific forms of social support (unit support, post deployment social support), resilience fully mediated the relationship between unit support and PTSD and depressive symptoms (Cunningham et al., 2014; Pietrzak et al., 2010; Smith et al., 2013). Similar to Smith and colleagues (2013) conclusions regarding the interaction between resilience, social support, and self-efficacy, it was suggested that unit increases in 
resilience may enhance self-efficacy and feelings of personal control, and efficacious coping styles (Bartone, 2006; Pietrzak et al., 2010; Pietrzak \& Southwick, 2011).

A unique feature of the present study is the exploration of both psychosocial and a behavioral predictor of resilience. The researchers hypothesized that physical activity (measured as METs) would both be positively correlated with resilience and significant predictor of resilience. Participation in physical activity and levels of physical fitness were both associated with buffering of stress symptoms (Hegberg \& Tone, 2015; Taylor et al., 2008). Researchers had observed that the connection between physical activity and resilience could be attributed to cognitive and emotional experiences during physical activity, such as self-efficacy, social engagement, and increased sense of control (Gaudlitz, von Lindenberger, Zschucke, \& Strohle, 2013). Thus, it was surprising that resilience was not significantly correlated with physical activity, nor did it present as a significant predictor in the regression model. These observations could be due to ceiling effects given that the estimated MET values from this study indicate a highly active sample. These speculations are like since much of the sample was recruited from a physical and social activity-based non-profit. Thus the sample may report higher levels of physical activity than general service member and Veteran populations. Self-selection bias from this recruitment process could have also introduced some issues with the data as many highly active individuals may have shown interest in this study. It would be beneficial to have a more objective measure of physical activity to evaluate for the relationship between physical fitness and resilience.

\section{Research Question 2}

The second research question compared resilience scores between those who did or did not participate in a resilience training program during their time in the military. Resilience scores 
were significantly higher in those who reported that they had received training as opposed to not. Additionally, within the hierarchical regression, resilience training was also found to be a significant predictor of resilience when controlling for other demographic variables. The purpose of the present study was not to evaluate the effectiveness of resilience training programs, rather explore predictors of resilience and capture an overview of resilience scores compared between groups using a measurement that had been tested with both military and non-military samples. In an evaluation of the Comprehensive Soldier and Family Fitness Program (CSF2), units that had a Master Resilience Training, who delivered resilience training, self-reported higher resilience and psychological health (Harms et al., 2013). In another study examining the Master Resilience Training in Army National Guard Soldiers, over 90\% of the participants reported that the training modules were helpful and 96\% reported using the MRT skills in their military job (Griffith \& West, 2013). It should also be noted that the sample in the Griffith and West (2013) study included both military and civilian contractors that completed the MRT program, and may not be generalizable to only military personnel MRTs or those delivered the unit-based training from the MRT military leadership.

Group differences in resilience were recognized between those who had and had not received training, but the significance of these differences decreased when controlling for other demographic data. It was surprising to see a high percentage of individuals who had not received training given that the Army has required all Active Duty service members to complete a certain number of hours of unit-level resilience training since 2014. There are three central explanations that could have contributed to this finding. First, the inclusion of both Active Duty and Veteran service members could mean that many participants could have transitioned out of service prior to the 2014 resilience training regulation. Secondly, the question was deliberately vague since 
the present study was not affiliated or funded by the Department of Defense or military contractors facilitating the delivery of the resilience. The researcher did not cite the Comprehensive Solider and Family Fitness program specifically, which has become to primary source of resilience training in the Army. Lastly, soldiers receive and complete numerous trainings per year and the sheer volume of training demands on the service members could have contributed to either the individual not completing the training as of the date of data collection, or the possible inclusion of resilience training in another titled training course.

\section{Research Question 3}

The final research question examined if and how demographic variables might predict variation in resilience. Statistically significant differences in resilience scores were found for gender and education. The mean scores of this study were similar to those found in Active Duty military personnel (Prabhakaran et al., 2012), and slightly higher than a sample of Stryker Battalion combat troops (Hammermeister, Pickering, McGraw, \& Ohlson, 2012), and a community sample of military Veterans (Green et al., 2014).

Covariates that were controlled for could have represented factors that were an added buffer for stress from a military standpoint (Cunningham et al, 2014). In the hierarchical multiple regression, gender and education were found to be predictors of resilience. Using an independent samples t-test, resilience scores were found to be significantly higher in males than females which was contrary to a study finding that females scored higher than males (Davidson et al., 2005). Variation in resilience based on marital status and education have not been explored extensively in the literature and warrant further examination. Surprisingly, differences were not significant based on duration of service under the possible assumption that those serving longer experience more adversity and thus more opportunities to become resilient. 
Explanations for the demographic variables emergence as significant or not significant could be attributed to aspects of the sample itself. Research has shown that spousal support is an integral part of the protective network that supports a soldiers resilience (Riggs \& Riggs, 2011). The connection between support of a significant (especially married) significant other can contribute to an Active Duty service member or Veteran's resilience. Additionally, the CSF2 resilience training programs include a component to train spouses of military personnel to be Master Resilience Trainers, increasing their role in the development of resilient qualities for their significant other (Dunning \& Raymond, 2013). Continued exploration of how spousal support contributes to resilience is warranted.

Education can also act as a buffer to stressors as those who have or are currently engaging in academic pursuits could have added support networks and resources to allow them to effectively manage challenges and contribute to resilience outcomes in the face of daily or military-oriented adversity. A large percentage of the participants had obtained a bachelors' or masters' degree or were currently pursuing a degree. Researchers examining community samples have found a positive relationship between education and resilience (Campbell-Sills et al., 2009), while others did not find the relationship between education and resilience to be significant (Lamond et al., 2008). An additional theory for the high education status is the increase in overall bachelor's degrees obtained by military personnel- particularly officers and warrant officers which made up slightly one third of the sample (compared with approximately one fourth of the overall active military population) (Military One Source, 2014). The GI bill, or opportunity for soldiers to return to school to finish or complete an advanced degree could have also contributed to the higher education status when specifically taking into account Veterans and part-time service members (National Guard and Reservists). Further explorations of military 
service members and demographic characteristics that may influence resilient qualities should include inquiries of MOS, or Military Occupation Specialty which designates one's role within the military, and an individual's rank to gather a more complete picture of the military service.

Additionally, gathering MOS could have impacted the data by identifying the types of jobs, responsibilities, experience, and challenges associated with individual tasks of military service. The present study did not differentiate those serving mainly in intelligence analysis or informational technology roles from those engaging in combat more frequently such as those in special operations branches of the US Military. Unique demands, qualifications, and experiences can shape the development of one's resilience over time.

\section{Limitations and Recommended Future Research}

This study was a convenience sample of Army service members and Army Veterans and may not be generalizable to the Army as a whole or to other branches of the US military that might have different exposures to resilience training and demands of service. All measures were self-report and subject to social desirability and rater bias. General resilience was only measured at one point which may lack sensitivity to measure variations in acute or chronic stress over time such as those accompanying military service and post-service Veteran transitions. Many of the participants were recruited through Team Red, White, and Blue which is a physical and social activity based non-profit for soldiers and Veterans which could have contributed to the homogenous sample in regards to physical activity, significant relationships between resilience scores and physical activity could have been more visible in a sample that included a more representative population of Active Duty service members and Veterans.

It was noted that there are differences in the quantity and quality of resilience training in the military and there are large differences between Master Resilience Training (MRT) and site- 
delivered unit based resilience training which is disseminated by leadership who are certified as MRT trainers. The volume and intensity of the resilience training varies greatly between the two which may not have been adequately accounted for in the present study.

Additionally, the sample included missing data which is inevitable with survey research. The small sample size may have reduced the statistical power and limited our chances of observing significant predictors such as physical activity. One challenge when working with this population is the high volume of studies conducted with the military, thus survey fatigue could be a major concern. Additionally, as with many other studies (see Lee et al., 2013 for review), the sample was relatively homogenous and subject to self-selection bias. The sampling methods of convenience and snowball sampling contribute to the possibility of the sample not being a clear reflection of US Army Active Duty and Veteran service member population as a whole. Lastly, the study could have been strengthened by collecting additional data including rank, MOS, and deployment status/number of deployments to get a more vivid picture of the demands faced, experiences acquired, and qualifications of the sample. This information would be beneficial to collect in the continued study of resilient qualities in the military.

Resilient qualities can also be explored in more specific sub-samples of the US Army or other branches, specifically those who have experienced PTSD, and/or other psychological or physical challenges. Resilient qualities are cultivated through both the experience of and positive adaption to perceived trauma or stress. It would beneficial to further study one's exposure to or perceived exposure to combat situations or other military-specific sources of trauma.

The study predictors of resilience in the military would benefit from longitudinal designs in order to evaluate how resilience might change over a portion of the lifetime, military career, or during pre and post-deployment. This could inform targeted resilience training programs that 
support specific skills when they are most needed, i.e. optimism early on in one's career and social support prior to transition out of service. Life stress could be viewed as a potential confounding factor when evaluating predictors of resilience thus future studies could try to control or measure life stress in conjunction with resilience. Inquiries on other branches of the military would be beneficial as they do not have mandated resilience training and perhaps encounter different challenges and demands that could fuel the development of resilience.

As discussed in the expanded review of literature, constructs such as post-traumatic growth, mental toughness, grit, hardiness, and coping can have some overlap or similar characteristics to resilience. It would be beneficial to explore their role in protective factors that buffer the effects of stress and adversity associated with military service. Few studies exist exploring the relationship of related construct to physical activity- thus another path warranted exploration. Researchers seeking to conduct a similar study should consider a longer and more comprehensive measure for social support, a larger sample size for additional power, and more complex analyses such as structural equation modeling to evaluate mediation. In conjunction with a larger sample size, many studies are conducted with white American males and a more diverse sample could help identify how resilience varies across cultural differences (J. H. Lee et al., 2013). In addition to culture, religion could play a vital role in the development of resilient qualities, and it would be useful to examine predictors of spiritual resilience, as designated as a component of the CSF2 resilience training program. The functionality of faith can be vital piece of how soldiers encounter and overcome adversity.

Cross-sectional designs are helpful to show relationships between predictors and a strength of this exploratory study lies in the civilian researcher inquiring the usefulness of the resilience training program. However, more robust experimental designs such as RCTs would be 
a valuable effort to uncover the impact that such programs have on soldier well-being, adjustment, and resilience (Meredith et al., 2011). Additionally, longitudinal and/or RCT studies could also more empirically navigate if and how physical activity might enhance resilience and the methods by which this process assuages mental health risks in various military and Veteran populations (Hegberg \& Tone, 2015), this could be particularly beneficial for Veterans as their occupational physical activity likely decreases following transition into civilian life.

\section{Practical Implications}

The above limitations withstanding, the present study has important practical implications. Specifically, training programs that target optimism as a central pillar to promote resilience and help soldiers cope with emotional distress are supported (Casey Jr, 2011). Additionally, programs can benefit from incorporating any means of improving coping selfefficacy in soldiers. Optimism is one of the core competencies of the resilience curriculum currently utilized by the United States Army. Optimism is seen as the "engine of resilience" and is used to help a soldier "hunt the good stuff" in the most challenging of situations. Optimism could be used in real time resilience to fight back against counterproductive thoughts that get in the way of optimal performance when it matters most. This could be implemented by self-talk interventions by sport or performance-focused practitioners.

The ability to help military personnel cultivate both optimism and coping self-efficacy is beneficial on the front-end, as a proactive strategy rather than reactive in the face of adversity. Using the tools of cognitive training can contribute to deliberate thinking. For instance, guided imagery and positive self-talk can be implemented with soldiers in a manner that fosters optimism and coping self-efficacy. This could be implemented by working with soldiers to develop guided imagery scripts or audio files that stimulate such images. Over time, these guided 
imagery files might be stored as libraries for future use. Once these imagery skills are developed on the front end, soldiers are armed with additional psychological armor when encountering the monumental stress of military service. In unknown situations, which are a guarantee in military service, optimism and coping self-efficacy can help guide an individual to the most controllable aspects of a situation and persist through difficult times.

Current programming utilizes optimism in this manner, however there are avenues in which to support these efforts by increasing soldiers coping self-efficacy. This could entail a reflection on the best performances under pressure, reinforcing the resilience the soldier has cultivated even early on in training, and discussion of how to handle already-anticipated adversity. Coping self-efficacy is often about strengthening pathways to support, including social support from one's unit, family, and friends. It would be helpful to reinforce the importance of these networks and increase the variance in availability of such resources throughout resilience training and throughout military service. A critical step in this process is to address and counter the stigma associated with asking for help or support, and instead see this as a social strengthening mechanisms of resourcefulness and unity.

Active Duty service members, Veterans, military families and spouses, civilian military contractors, organizations supporting soldiers and Veterans are all active stakeholders in creating a military force increasingly capable of coping with stress and adversity. There exists an enormous personal, institutional, economic, and emotional cost related to challenges that military personnel and Veterans volunteer to endure and the identification and development of resilient qualities can be an effort to assuage some of this cost and support the well-being of military personnel. The findings of the present study contribute knowledge relevant to the movement 
towards proactive and preventative measures to enhance resilient characteristics and support our nation's service members.

\section{Conclusions}

In conclusion, the present study sheds light on possible demographic differences in resilience of a military sample. Males scored higher on resilience than women, age was not a significant predictor of resilience, education had a slightly significant relationship with resilience, and marital status was a significant predictor- revealing a potentially important piece of social support. Participants who reported completing resilience training scored higher on resilience than those who reported not having completed the training Most critically, it was found that optimism and self-efficacy were significant predictors of resilience, which carries strong support and additional considerations for existing resilience training efforts.

While optimism is a central component of resilience training programs, the addition of programming to bolster soldier coping self-efficacy warrants consideration. To build coping selfefficacy, resilience training can strengthen or create additional resource networks for soldiers to their social community and internal resources. The research supports the notion that resilience can be developed and this could happen through identifying paths to an optimistic mindset and supporting internal (visualization, meditation, problem-solving, self-talk) and external (unit support, recreational activities, friends and family) resources. It was clear that optimism and coping self-efficacy were predictors of resilience in this study, however they are not the only predictors of resilience and comprehensive models examining other variables such as PostTraumatic Growth or grit would be beneficial to support the current resilience research in community, clinical, and military-based samples.

\section{References}


Adler, A. B., Vaitkus, M. A., \& Martin, J. A. (1996). Combat exposure and posttraumatic stress symptomatology among US soldiers deployed to the Gulf war. Military Psychology, 8(1), $1-16$.

Agaibi, C. E., \& Wilson, J. P. (2005). Trauma, PTSD, and resilience a review of the literature. Trauma, Violence, \& Abuse, 6(3), 195-216.

Alexander, C. (1998). The endurance: Shackleton's legendary antarctic expedition. New York: Alfred A. Knopf.

Aneshensel, C. S. (1992). Social stress: Theory and research. Annual Review of Psychology, 1538.

Anestis, M. D., Khazem, L. R., Mohn, R. S., \& Green, B. A. (2015). Testing the main hypotheses of the interpersonal-psychological theory of suicidal behavior in a large diverse sample of United States military personnel. Comprehensive Psychiatry, 60, 7885.

Ano, G. G., \& Vasconcelles, E. B. (2005). Religious coping and psychological adjustment to stress: A meta-analysis. Journal of Clinical Psychology, 61(4), 461-480.

Baecke, J., Burema, J., \& Frijters, J. (1982). A short questionnaire for the measurement of habitual physical activity in epidemiological studies. The American Journal of Clinical Nutrition, 36(5), 936-942.

Bartone, P. T. (2006). Resilience under military operational stress: can leaders influence hardiness? Military Psychology, 18(S), S131-S148. 
Beckham, J. C., Crawford, A. L., Feldman, M. E., Kirby, A. C., Hertzberg, M. A., Davidson, J., \& Moore, S. D. (1997). Chronic posttraumatic stress disorder and chronic pain in Vietnam combat veterans. Journal of Psychosomatic Research, 43(4), 379-389.

Benight, C. C., \& Bandura, A. (2004). Social cognitive theory of posttraumatic recovery: the role of perceived self-efficacy. Behaviour Research and Therapy, 42(10), 1129-1148. doi:http://dx.doi.org/10.1016/j.brat.2003.08.008

Benight, C. C., Freyaldenhoven, R. W., Hughes, J., Ruiz, J. M., Zoschke, T. A., \& Lovallo, W. R. (2000). Coping Self-Efficacy and Psychological Distress Following the Oklahoma City Bombing1. Journal of Applied Social Psychology, 30(7), 1331-1344.

Benight, C. C., Ruzek, J. I., \& Waldrep, E. (2008). Internet interventions for traumatic stress: A review and theoretically based example. Journal of Traumatic Stress, 21(6), 513-520.

Benight, C. C., Swift, E., Sanger, J., Smith, A., \& Zeppelin, D. (1999). Coping self-efficacy as a mediator of distress following a natural disaster. Journal of Applied Social Psychology, 29(12), 2443-2464.

Bernard, B. (1997). Turning it around for all youth: From risk to resilience (Report No. EDOUD-97-7). New York, NY: office of Educational Research and Improvement (ERIC Document Reproduction Service No. ED412309).

Beutel, M. E., Glaesmer, H., Decker, O., Fischbeck, S., \& Brähler, E. (2009). Life satisfaction, distress, and resiliency across the life span of women. Menopause, 16(6), 1132-1138.

Blair, S. N. (1984). How to assess exercise habits and physical fitness. Hoboken, N.J. : John Wiley \& Sons. 
Block, J. H., \& Block, J. (1980). The role of ego-control and ego-resiliency in the organization of behavior. Paper presented at the Development of cognition, affect, and social relations: The Minnesota symposia on child psychology.

Boermans, S., Delahaij, R., Korteling, J., \& Euwema, M. (2012). Training resilience for highrisk environments: towards a strength-based approach within the military. Hoboken, NJ: Blackwell Publishing.

Bonanno, G. A. (2004). Loss, trauma, and human resilience: have we underestimated the human capacity to thrive after extremely aversive events? American Psychologist, 59(1), 20-35.

Bonanno, G. A. (2004). Loss, Trauma, and Human Resilience: Have We Underestimated the Human Capacity to Thrive After Extremely Aversive Events? American Psychologist, 59(1), 20-28. doi:10.1037/0003-066x.59.1.20

Bonanno, G. A., Galea, S., Bucciarelli, A., \& Vlahov, D. (2007). What predicts psychological resilience after disaster? The role of demographics, resources, and life stress. Journal of Consulting and Clinical Psychology, 75(5), 671-682.

Bowles, S. V., \& Bates, M. J. (2010). Military organizations and programs contributing to resilience building. Military Medicine, 175(6), 382-385.

Brennan, M. A. (2008). Conceptualizing resiliency: An interactional perspective for community and youth development. Child Care in Practice, 14(1), 55-64.

Campbell-Sills, L., Cohan, S. L., \& Stein, M. B. (2006). Relationship of resilience to personality, coping, and psychiatric symptoms in young adults. Behavior Research and Therapy, 44(4), 585-599. 
Campbell-Sills, L., Forde, D. R., \& Stein, M. B. (2009). Demographic and childhood environmental predictors of resilience in a community sample. Journal of Psychiatric Research, 43(12), 1007-1012. doi:http://dx.doi.org/10.1016/j.jpsychires.2009.01.013

Campbell-Sills, L., \& Stein, M. B. (2007). Psychometric analysis and refinement of the connordavidson resilience scale (CD-RISC): Validation of a 10-item measure of resilience. Journal of Traumatic Stress, 20(6), 1019-1028.

Carver, C. S., Scheier, M. F., \& Segerstrom, S. C. (2010). Optimism. Clinical Psychology Review, 30(7), 879-889.

Casey Jr, G. W. (2011). Comprehensive soldier fitness: a vision for psychological resilience in the US Army. American Psychologist, 66(1), 1-3.

Charuvastra, A., \& Cloitre, M. (2008). Social bonds and posttraumatic stress disorder. Annual Review of Psychology, 59, 301-327.

Chesney, M. A., Neilands, T. B., Chambers, D. B., Taylor, J. M., \& Folkman, S. (2006). A validity and reliability study of the coping self-efficacy scale. British Journal of Health Psychology, 11(3), 421-437.

Cody, J. A. (2013). The roles of stress appraisal and self-efficacy in fostering resilience to improve psychosocial outcomes following negative life events among college students: A multiple mediation analysis. University of Tennessee. Knoxville, TN.

Cohen, J. (1977). Statistical power analysis for the behavioral sciences (revised ed.): New York: Academic Press.

Condly, S. J. (2006). Resilience in children a review of literature with implications for education. Urban Education, 41(3), 211-236. 
Connor, K. M., \& Davidson, J. R. T. (2003). Development of a new resilience scale: The Connor-Davidson Resilience Scale (CD-RISC). Depression and Anxiety, 18(2), 76-82. doi:10.1002/da.10113

Cornum, R., Matthews, M. D., \& Seligman, M. E. (2011). Comprehensive Soldier Fitness: Building Resilience in a Challenging Institutional Context. American Psychologist, 66(1), 4-9.

Costa, P., Terracciano, A., \& McCrae, R. R. (2001). Gender differences in personality traits across cultures: robust and surprising findings. Journal of Personality and Social Psychology, 81(2), 322-340.

Crane, M., Lewis, V., Cohn, A. D., Hodson, S. E., Parslow, R., Bryant, R. A., . . Forbes, D. (2012). A protocol for the longitudinal study of psychological resilience in the Australian Defence Force. Journal of Military and Veterans Health, 20(4), 36-48.

Crews, D. J., \& Landers, D. M. (1987). A meta-analytic review of aerobic fitness and reactivity to psychosocial stressors. Medicine \& Science in Sports \& Exercise, 114-120.

Crust, L. (2007). Mental toughness in sport: A review. International Journal of Sport and Exercise Psychology, 5(3), 270-290.

Crust, L., \& Azadi, K. (2010). Mental toughness and athletes' use of psychological strategies. European Journal of Sport Science, 10(1), 43-51.

Cunningham, C. A., Weber, B. A., Roberts, B. L., Hejmanowski, T. S., Griffin, W. D., \& Lutz, B. J. (2014). The role of resilience and social support in predicting postdeployment adjustment in otherwise healthy navy personnel. Military Medicine, 179(9), 979-985.

Davidson, J., \& Connor, K. M. (2015). Connor-Davidson Resilience Scale (CD-RISC) Manual. Manual. 
Davidson, J., Payne, V. M., Connor, K. M., Foa, E. B., Rothbaum, B. O., Hertzberg, M. A., \& Weisler, R. H. (2005). Trauma, resilience and saliostasis: effects of treatment in posttraumatic stress disorder. International Clinical Psychopharmacology, 20(1), 43-48.

Davydov, D. M., Stewart, R., Ritchie, K., \& Chaudieu, I. (2010). Resilience and mental health. Clinical Psychology Review, 30(5), 479-495.

Deuster, P. A., \& Silverman, M. N. (2013). Physical fitness: a pathway to health and resilience. US Army Medical Department Journal, 24-35.

Duckworth, A. L., Kirby, T. A., Tsukayama, E., Berstein, H., \& Ericsson, K. A. (2011). Deliberate practice spells success why grittier competitors triumph at the national spelling bee. Social Psychological and Personality Science, 2(2), 174-181.

Duckworth, A. L., Peterson, C., Matthews, M. D., \& Kelly, D. R. (2007). Grit: perseverance and passion for long-term goals. Journal of Personality and Social Psychology, 92(6), 1087.

Duckworth, A. L., \& Quinn, P. D. (2009). Development and validation of the Short Grit Scale (GRIT-S). Journal of Personality Assessment, 91(2), 166-174.

Dunn, L. B., Iglewicz, A., \& Moutier, C. (2008). A conceptual model of medical student wellbeing: promoting resilience and preventing burnout. Academic Psychiatry, 32(1), 44-53.

Dunning, I., \& Raymond, M. (2013). Sustaining Comprehensive Soldier and Family Fitness: Critical for Army 2020. Retrieved from ARMY WAR COLLEGE CARLISLE BARRACKS PA.:

Eskreis-Winkler, L., Shulman, E. P., Beal, S. A., \& Duckworth, A. L. (2014). The grit effect: Predicting retention in the military, the workplace, school and marriage. Frontiers in Psychology, 5, 1-12. 
Fletcher, D., \& Sarkar, M. (2012). A grounded theory of psychological resilience in Olympic champions. Psychology of Sport and Exercise, 13(5), 669-678. doi:http://dx.doi.org/10.1016/j.psychsport.2012.04.007

Fletcher, D., \& Sarkar, M. (2013). Psychological resilience: A review and critique of definitions, concepts, and theory. European Psychologist, 18(1), 12-23.

Folkman, S., \& Moskowitz, J. T. (2004). Coping: Pitfalls and promise. Annual Review of Psychology, 55, 745-774.

Fredrickson, B. L. (2001). The role of positive emotions in positive psychology: The broadenand-build theory of positive emotions. American Psychologist, 56(3), 218-226.

Fredrickson, B. L. (2004). The broaden-and-build theory of positive emotions. Philosophical transactions-royal society of london series b biological sciences, 1367-1378.

Galli, N., \& Vealey, R. S. (2008). Bouncing back” from adversity: Athletes' experiences of resilience. The Sport Psychologist, 22(3), 316-335.

Garmezy, N. (1975). The experimental study of children vulnerable to psychopathology. Child Personality and Psychopathology: Current Topics, 2, 19-36.

Garmezy, N. (1991). Resilience and vulnerability to adverse developmental outcomes associated with poverty. American Behavioral Scientist.

Garmezy, N., Masten, A. S., \& Tellegen, A. (1984). The study of stress and competence in children: A building block for developmental psychopathology. Child Development, 97111.

Gaudlitz, K., von Lindenberger, B., Zschucke, E., \& Strohle, A. (2013). Mechanisms underlying the relationship between physical activity and anxiety: human data. In P. Ekkekakis (Ed.), 
Routledge handbook of physical activity and mental health (pp. 117-129). London:

Routledge

Gerber, M., \& Pühse, U. (2009). Review Article: Do exercise and fitness protect against stressinduced health complaints? A review of the literature. Scandinavian Journal of Public Health, 37(8), 801-819. doi:10.1177/1403494809350522

Gillespie, B. M., Chaboyer, W., \& Wallis, M. (2009). The influence of personal characteristics on the resilience of operating room nurses: A predictor study. International Journal of Nursing Studies, 46(7), 968-976.

Ginzburg, K., Solomon, Z., Dekel, R., \& Neria, Y. (2003). Battlefield functioning and chronic PTSD: associations with perceived self efficacy and causal attribution. Personality and Individual Differences, 34(3), 463-476.

Green, K. T., Calhoun, P. S., Dennis, M. F., \& Beckham, J. C. (2010). Exploration of the resilience construct in posttraumatic stress disorder severity and functional correlates in military combat veterans who have served since September 11, 2001. The Journal of Clinical Psychiatry, 71(7), 1,478-830.

Green, K. T., Hayward, L. C., Williams, A. M., Dennis, P. A., Bryan, B. C., Taber, K. H., .. . Ingle, S. J. (2014). Examining the Factor Structure of the Connor-Davidson Resilience Scale (CD-RISC) in a Post-9/11 US Military Veteran Sample. Assessment, 21(4), 443451.

Griffith, J., \& West, C. (2013). Master resilience training and its relationship to individual wellbeing and stress buffering among Army National Guard soldiers. The Journal of Behavioral Health Services \& Research, 40(2), 140-155. 
Grzywacz, J. G., \& Marks, N. F. (2001). Social inequalities and exercise during adulthood: toward an ecological perspective. Journal of Health and Social Behavior, 202-220.

Gucciardi, D. F., Gordon, S., \& Dimmock, J. A. (2008). Towards an understanding of mental toughness in Australian football. Journal of Applied Sport Psychology, 20(3), 261-281.

Hamill, S. K. (2003). Resilience and self-efficacy: The importance of efficacy beliefs and coping mechanisms in resilient adolescents. Colgate University Journal of the Sciences, 35, 115 146.

Hammermeister, J., Pickering, M. A., McGraw, L., \& Ohlson, C. (2012). The relationship between sport related psychological skills and indicators of PTSD among stryker brigade soldiers: the mediating effects of perceived psychological resilience. Journal of Sport Behavior, 35(1), 40-60.

Harms, P. D., Herian, M., Krasikova, D. V., Vanhove, A. J., \& Lester, P. B. (2013). The Comprehensive Soldier and Family Fitness program evaluation report\# 4: Evaluation of resilience training and mental and behavioral health outcomes. (Report No. 4). , 1-28. Retrieved from http://csf2.army.mil/

Hegberg, N. J., \& Tone, E. B. (2015). Physical activity and stress resilience: Considering those at-risk for developing mental health problems. Mental Health and Physical Activity, 8, 17.doi:http://dx.doi.org/10.1016/j.mhpa.2014.10.001

Hendricks Thomas, K., Plummer Taylor, S., Hamner, K., Glazer, J., \& Kaufman, E. (2015). Multi-site Programming Offered to Promote Resilience in Military Veterans: A Process Evaluation of the Just Roll With It Bootcamps. Californian Journal of Health Promotion, $13(2), 15-24$. 
Holahan, C. J., Moos, R. H., Holahan, C. K., \& Brennan, P. L. (1995). Social support, coping, and depressive symptoms in a late-middle-aged sample of patients reporting cardiac illness. Health Psychology, 14(2), 152-170.

Horowitz, M., Wilner, N., \& Alvarez, W. (1979). Impact of Event Scale: a measure of subjective stress. Psychosomatic Medicine, 41(3), 209-218.

Hourani, L., Bender, R. H., Weimer, B., Peeler, R., Bradshaw, M., Lane, M., \& Larson, G. (2012). Longitudinal study of resilience and mental health in marines leaving military service. Journal of Affective Disorders, 139(2), 154-165.

Hu, T., Zhang, D., \& Wang, J. (2015). A meta-analysis of the trait resilience and mental health. Personality and Individual Differences, 76(0), 18-27. doi:http://dx.doi.org/10.1016/j.paid.2014.11.039

Jaeschke, A.-M. C., Sachs, M. L., \& Dieffenbach, K. D. (2016). Ultramarathon Runners’ Perceptions of Mental Toughness: A Qualitative Inquiry. The Sport Psychologist, 30(3), 242-255.

Johnson, D. C., Polusny, M. A., Erbes, C. R., King, D., King, L., Litz, B. T., . . Southwick, S. M. (2011). Development and initial validation of the Response to Stressful Experiences Scale. Military Medicine, 176(2), 161-169.

Karademas, E. C. (2006). Self-efficacy, social support and well-being: The mediating role of optimism. Personality and Individual Differences, 40(6), 1281-1290. doi:http://dx.doi.org/10.1016/j.paid.2005.10.019

Kaylor, J. A., King, D. W., \& King, L. A. (1987). Psychological effects of military service in Vietnam: a meta-analysis. Psychological Bulletin, 102(2), 257-264. 
King, L. A., King, D. W., Fairbank, J. A., Keane, T. M., \& Adams, G. A. (1998). Resiliencerecovery factors in post-traumatic stress disorder among female and male Vietnam veterans: Hardiness, postwar social support, and additional stressful life events. Journal of Personality and Social Psychology, 74(2), 420-435.

Klein, K. J., \& Zedeck, S. (2004). Introduction to the Special Section on Theoretical Models and Conceptual Analyses: Theory in Applied Psychology: Lessons (Re) Learned. Journal of Applied Psychology, 89(6), 931.

Kobasa, S. C. (1979). Stressful life events, personality, and health: An inquiry into hardiness. Journal of Personality and Social Psychology, 37(1), 1-11. doi:10.1037/00223514.37.1.1

Kohl, H. W., Blair, S. N., Paffenbarger, R. S., Macera, C. A., \& Kronenfeld, J. J. (1988). A mail survey of physical activity habits as related to measured physical fitness. American Journal of Epidemiology, 127(6), 1228-1239.

Lamond, A. J., Depp, C. A., Allison, M., Langer, R., Reichstadt, J., Moore, D. J., . . Jeste, D. V. (2008). Measurement and predictors of resilience among community-dwelling older women. Journal of Psychiatric Research, 43(2), 148-154.

Lazarus, R. S., \& Folkman, S. (1984). Stress, appraisal, and coping. New York Springer publishing company.

Lee, H., Brown, S. L., Mitchell, M. M., \& Schiraldi, G. R. (2008). Correlates of resilience in the face of adversity for Korean women immigrating to the US. Journal of Immigrant and Minority Health, 10(5), 415-422.

Lee, J. E., Sudom, K. A., \& McCreary, D. R. (2011). Higher-order model of resilience in the Canadian forces. Canadian Journal of Behavioural Science, 43(3), 222-230. 
Lee, J. H., Nam, S. K., Kim, A. R., Kim, B., Lee, M. Y., \& Lee, S. M. (2013). Resilience: A Meta-Analytic Approach. Journal of Counseling \& Development, 91(3), 269-279. doi:10.1002/j.1556-6676.2013.00095.x

Leipold, B., \& Greve, W. (2009). Resilience: A conceptual bridge between coping and development. European Psychologist, 14(1), 40-50.

Luthans, F., Avolio, B. J., Avey, J. B., \& Norman, S. M. (2007). POSITIVE PSYCHOLOGICAL CAPITAL: MEASUREMENT AND RELATIONSHIP WITH PERFORMANCE AND SATISFACTION. Personnel Psychology, 60(3), 541-572. doi:10.1111/j.1744-6570.2007.00083.x

Luthar, S. S., Cicchetti, D., \& Becker, B. (2000). The Construct of Resilience: A Critical Evaluation and Guidelines for Future Work. Child Development, 71(3), 543-562. doi:10.1111/1467-8624.00164

Lyons, J. (1991). Strategies for assessing the potential for positive adjustment following trauma. Journal of Traumatic Stress, 4(1), 93-111. doi:10.1007/BF00976011

Maddi, S. R. (2005). On hardiness and other pathways to resilience. The American Psychologist, $60(3), 261-267$.

Maguen, S., Turcotte, D. M., Peterson, A. L., Dremsa, T. L., Garb, H. N., McNally, R. J., \& Litz, B. T. (2008). Description of risk and resilience factors among military medical personnel before deployment to Iraq. Military Medicine, 173(1), 1-9.

Major, B., Richards, C., Cooper, M. L., Cozzarelli, C., \& Zubek, J. (1998). Personal resilience, cognitive appraisals, and coping: an integrative model of adjustment to abortion. Journal of Personality and Social Psychology, 74(3), 735-745. 
Masten, A. S. (2001). Ordinary magic: Resilience processes in development. American Psychologist, 56(3), 227-238.

Masten, A. S. (2007). Resilience in developing systems: Progress and promise as the fourth wave rises. Development and psychopathology, 19(03), 921-930.

Masten, A. S., Best, K. M., \& Garmezy, N. (1990). Resilience and development: Contributions from the study of children who overcome adversity. Development and psychopathology, 2(04), 425-444. doi:doi:10.1017/S0954579400005812

McGloin, J. M., \& Widom, C. S. (2001). Resilience among abused and neglected children grown up. Development and Psycholopathology, 13(04), 1021-1038.

Meredith, L. S., Sherbourne, C. D., \& Gaillot, S. J. (2011). Promoting psychological resilience in the US military: Rand Corporation.

Milliken, C. S., Auchterlonie, J. L., \& Hoge, C. W. (2007). Longitudinal assessment of mental health problems among active and reserve component soldiers returning from the Iraq war. Journal of the American Medical Association, 298(18), 2141-2148.

Min, J.-A., Jung, Y.-E., Kim, D.-J., Yim, H.-W., Kim, J.-J., Kim, T.-S., . . Chae, J.-H. (2013). Characteristics associated with low resilience in patients with depression and/or anxiety disorders. Quality of Life Research, 22(2), 231-241.

Mummery, W. K., Schofield, G., \& Perry, C. (2004). Bouncing back: the role of coping style, social support and self-concept in resilience of sport performance. Athletic Insight, 6(3), $1-15$.

Nolen-Hoeksema, S. (1991). Responses to depression and their effects on the duration of depressive episodes. Journal of Abnormal Psychology, 100(4), 569-582. 
Odierno, R. T. (2014). Army Regulation 350-53. Training: Comprehensive Soldier and Family Fitness. Retrieved from http://www.apd.army.mil/pdffiles/r350_53.pdf.

Paffenbarger Jr, R. S., Blair, S. N., Lee, I.-M., \& Hyde, R. T. (1993). Measurement of physical activity to assess health effects in free-living populations. Medicine and Science in Sports and Exercise, 25(1), 60-70.

Patterson, J. M. (2002). Integrating family resilience and family stress theory. Journal of Marriage and Family, 64(2), 349-360.

Perkins-Gough, D. (2013). The significance of grit: A conversation with Angela Lee Duckworth. Educational Leadership, 71(1), 14-20.

Peterson, C., Park, N., \& Castro, C. A. (2011). Assessment for the US Army Comprehensive Soldier Fitness program: the Global Assessment Tool. American Psychologist, 66(1), 1018.

Petros, N., Opacka-Juffry, J., \& Huber, J. H. (2013). Psychometric and neurobiological assessment of resilience in a non-clinical sample of adults. Psychoneuroendocrinology, 38(10), 2099-2108. doi:10.1016/j.psyneuen.2013.03.022

Pietrzak, R. H., \& Cook, J. M. (2013). Psychological resilience in older US veterans: results from the national health and resilience in veterans study. Depression and Anxiety, 30(5), 432-443.

Pietrzak, R. H., Johnson, D. C., Goldstein, M. B., Malley, J. C., Rivers, A. J., Morgan, C. A., \& Southwick, S. M. (2010). Psychosocial buffers of traumatic stress, depressive symptoms, and psychosocial difficulties in veterans of Operations Enduring Freedom and Iraqi Freedom: The role of resilience, unit support, and postdeployment social support. Journal of Affective Disorders, 120(1), 188-192. doi:10.1016/j.jad.2009.04.015 
Pietrzak, R. H., \& Southwick, S. M. (2011). Psychological resilience in OEF-OIF Veterans: Application of a novel classification approach and examination of demographic and psychosocial correlates. Journal of Affective Disorders, 133(3), 560-568.

Polk, L. V. (1997). Toward a middle-range theory of resilience. Advances in Nursing Science, 19(3), 1-13.

Prabhakaran, J., Pflieger, J., Spera, C., Harvey, J., Travis, W., \& Foster, R. (2012). Air Force members health: Examining the Tenets of the Comprehensive Airmen Fitness (CAF) model in a worldwide survey of active duty members. Paper presented at the Military Health System Research Symposium (MHSRS), Fort Lauderdale, FL.

Reivich, K., Seligman, M. E., \& McBride, S. (2011a). Master resilience training in the US Army. American Psychologist, 66(1), 25-29.

Reivich, K., Seligman, M. E., \& McBride, S. (2011b). Master Resilience Training in the US Army.

Reivich, K., \& Shatte, A. (2002). The resilience factor: New York: Broadway Books.

Richardson, G. E. (2002). The metatheory of resilience and resiliency. Journal of Clinical Psychology, 58(3), 307-321. doi:10.1002/jclp.10020

Riggs, S. A., \& Riggs, D. S. (2011). Risk and resilience in military families experiencing deployment: The role of the family attachment network. Journal of Family Psychology, $25(5), 675-686$.

Riolli, L., \& Savicki, V. (2003). Information system organizational resilience. Omega, 31(3), 227-233. 
Robertson-Kraft, C., \& Duckworth, A. L. (2014). True grit: Trait-level perseverance and passion for long-term goals predicts effectiveness and retention among novice teachers. Teachers College Record, 116(3), 1-24.

Roth, D. L., Wiebe, D. J., Fillingim, R. B., \& Shay, K. A. (1989). Life events, fitness, hardiness, and health: a simultaneous analysis of proposed stress-resistance effects. Journal of Personality and Social Psychology, 57(1), 136-152.

Rutter, M. (1979). Protective factors in children's responses to stress and disadvantage. Annals of the Academy of Medicine, Singapore, 8(3), 324-338.

Rutter, M. (1985). Resilience in the face of adversity. British Journal of Psychiatry, 147(1), 598611.

Scheier, M. F., \& Carver, C. S. (1985). Optimism, coping, and health: assessment and implications of generalized outcome expectancies. Health Psychology, 4(3), 219-240.

Segovia, F., Moore, J. L., Linnville, S. E., Hoyt, R. E., \& Hain, R. E. (2012). Optimism predicts resilience in repatriated prisoners of war: A 37-year longitudinal study. Journal of Traumatic Stress, 25(3), 330-336.

Seligman, M. E., \& Csikszentmihalyi, M. (2000). Positive psychology: An introduction (Vol. 55). Netherlands: American Psychological Association.

Sinclair, V. G., \& Wallston, K. A. (2004). The development and psychometric evaluation of the Brief Resilient Coping Scale. Assessment, 11(1), 94-101.

Smith, A. J., Benight, C. C., \& Cieslak, R. (2013). Social support and postdeployment coping self-efficacy as predictors of distress among combat veterans. Military Psychology, 25(5), 452-477. 
Solomon, Z., Benbenishty, R., \& Mikulincer, M. (1991). The contribution of wartime, pre-war, and post-war factors to self-efficacy: A longitudinal study of combat stress reaction. Journal of Traumatic Stress, 4(3), 345-361.

Source, M. O. (2014). Demographics profile of the military community.

Southwick, S. M., \& Charney, D. S. (2012). Resilience: The science of mastering life's greatest challenges. New York: Cambridge University Press.

Southwick, S. M., Litz, B. T., Charney, D., \& Friedman, M. J. (2011). Resilience and mental health: Challenges across the lifespan. New York: Cambridge University Press.

Stanley, E. A., Schaldach, J. M., Kiyonaga, A., \& Jha, A. P. (2011). Mindfulness-based mind fitness training: A case study of a high-stress predeployment military cohort. Cognitive and Behavioral Practice, 18(4), 566-576.

Steinhardt, M., \& Dolbier, C. (2008). Evaluation of a resilience intervention to enhance coping strategies and protective factors and decrease symptomatology. Journal of American College Health, 56(4), 445-453.

Strohacker, K., Wing, R. R., \& McCaffery, J. M. (2013). Contributions of body mass index and exercise habits on inflammatory markers: a cohort study of middle-aged adults living in the USA. British Medical Journal Open, 3(5), 23-26.

Sumer, N., Karanci, A. N., Berument, S. K., \& Gunes, H. (2005). Personal resources, coping self-efficacy, and quake exposure as predictors of psychological distress following the 1999 earthquake in Turkey. Journal of Traumatic Stress, 18(4), 331-342.

Taylor, M. K., Markham, A. E., Reis, J. P., Padilla, G. A., Potterat, E. G., Drummond, S. P., \& Mujica-Parodi, L. R. (2008). Physical fitness influences stress reactions to extreme military training. Military Medicine, 173(8), 738-742. 
Tedeschi, R. G., \& Calhoun, L. G. (2004). Posttraumatic Growth: Conceptual Foundations and Empirical Evidence. Psychological Inquiry, 15(1), 1-18.

Thomas, J. L., Britt, T. W., Odle-Dusseau, H., \& Bliese, P. D. (2011). Dispositional optimism buffers combat veterans from the negative effects of warzone stress on mental health symptoms and work impairment. Journal of Clinical Psychology, 67(9), 866-880.

Tsai, J., Harpaz-Rotem, I., Pietrzak, R. H., \& Southwick, S. M. (2012). The role of coping, resilience, and social support in mediating the relation between PTSD and social functioning in veterans returning from Iraq and Afghanistan. Psychiatry, 75(2), 135-149.

Tugade, M. M., \& Fredrickson, B. L. (2004). Resilient individuals use positive emotions to bounce back from negative emotional experiences. Journal of Personality and Social Psychology, 86(2), 320.

Vanhove, A. J., Herian, M. N., Perez, A. L., Harms, P. D., \& Lester, P. B. (2015). Can resilience be developed at work? A meta-analytic review of resilience-building programme effectiveness. Journal of Occupational and Organizational Psychology, 1-30.

Waldrep, E. E. (2015). Coping Self-Efficacy as a Mechanism of Resilience following Traumatic Injury: A Linear Growth Model. Kent State University.

Washburn, R. A., Goldfield, S. R., Smith, K. W., \& McKinlay, J. B. (1990). The validity of selfreported exercise-induced sweating as a measure of physical activity. American Journal of Epidemiology, 132(1), 107-113.

Werner, E. E. (1993). Risk, resilience, and recovery: Perspectives from the Kauai Longitudinal Study. Development and psychopathology, 5(04), 503-515.

Werner, E. E. (1995). Resilience in development. Current Directions in Psychological Science, $4(3), 81-85$. 
Werner, E. E., \& Smith, R. S. (1992). Overcoming the odds: High risk children from birth to adulthood. New York: Cornell University Press.

Windle, G. (2011). What is resilience? A review and concept analysis. Reviews in Clinical Gerontology, 21(02), 152-169.

Windle, G., Bennett, K. M., \& Noyes, J. (2011). A methodological review of resilience measurement scales. Health and Quality of Life Outcomes, 9(8), 1-18.

Winwood, P. C., \& Lushington, K. (2006). Disentangling the effects of psychological and physical work demands on sleep, recovery and maladaptive chronic stress outcomes within a large sample of Australian nurses. Journal of Advanced Nursing, 56(6), 679-689.

Yehuda, R., Vermetten, E., McFarlane, A. C., \& Lehrner, A. (2014). PTSD in the military: Special considerations for understanding prevalence, pathophysiology and treatment following deployment. European Journal of Psychotraumatology, 5, 5-20.

Zimet, G. D., Dahlem, N. W., Zimet, S. G., \& Farley, G. K. (1988). The multidimensional scale of perceived social support. Journal of Personality Assessment, 52(1), 30-41. 
Appendix A

Participant Recruitment Advertisement and Informed Consent

\section{Research Study on Resilience in the Military}

The ultimate measure of a man is not where he stands in moments of comfort and convenience, but where he stands at times of challenge and controversy.

-Dr. Martin Luther King Jr. 
- Are you currently serving in the United States Army or a Veteran?

- Are you willing to help further the research on resilience?

If you answered YES to these questions, please consider taking the 10-minute survey (link below). The survey is completely anonymous and confidential. Army Reserves and National Guard are also eligible to participate.

Though you may hear "thank you" often, I don't feel it can ever be enough. Your sacrifices to our Nation have not gone unnoticed. It is an honor to work with amazing men and women who are still serving or Veteran service members of the US Army. Thank you for volunteering to support and defend the Constitution of the United States.

Please email Anna-Marie Jaeschke at ajaeschk@mix.wvu.edu if you have any questions.

$* * * * * * * * * * * * * * * \mathrm{LINK} * * * * * * * * * * * * * * * * * * * * *$

West Virginia University IRB Protocol: 1511924190

Dear Participant,

Foremost, thank you for your service to our Nation. Though you may hear "thank you" often, I don't feel it can ever be enough. Your sacrifices to our Nation have not gone unnoticed. It is an honor to work with amazing men and women who are still serving or Veteran service members of the US Army. Thank you for volunteering to support and defend the Constitution of the 


\section{United States.}

I am a doctoral student in Sport and Exercise Psychology at West Virginia University conducting a study for my dissertation entitled: Psychosocial Predictors of Resilience in the Military. I am reaching out to as many US Army service members and Veterans as possible to gather information on how certain factors contribute to resilience.

To complete the survey you must be Active Duty Army, US Army Reserve (USAR), or Army National Guard (ARNG) or be a Veteran of the US Army, USAR, or ARNG. Participants must be over the age of 18 and not have a serious mental illness. The survey ends with a page of mental health resources for service members and Veterans.

Your participation will require approximately 10 minutes. If you would like to participate, click start survey below.

You can stop the survey at any time without penalty. Information you provide will be completely confidential. Your responses will be anonymous and at no time will the researchers be collecting your name, birth date, or contact information.

I hope you will agree to participate in my study. I am happy to answer any questions you may have. You can reach me by email at ajaeschk@mix.wvu.edu.

Thank you kindly for your time and service.

Sincerely, Anna-Marie Jaeschke, Doctoral Student Peter Giacobbi, Faculty Supervisor 
Appendix B

\section{Battery of Measures}

\section{Demographic Questionnaire}

1. Age: Please enter your age in years:

2. Sex:

Female Male

3. What is your current marital status: 

1. Single
2. In Committed Relationship (Unmarried/Cohabitating)
3. Married
4. Separated
5. Divorced
6. Divorced and Re-Married
7. Widowed

4. Race:

1. African American/Black

2. American Indian/Alaskan Native

3. Asian

4. Biracial

5. Caucasian/White

6. Native Hawaiian/Pacific Islander

7. Don't Know

8. Other: (please specify)

5. Are you Hispanic or Latino?

Yes No

6. Level of Education (select highest degree obtained)

1. High School Diploma/GED

2. Some Undergraduate/Pursuing Degree

3. Bachelors Degree

4. Some Graduate/Pursuing Degree

5. Masters Degree

6. Professional/Doctoral Degree

7. In which general geographic location do you currently live/are stationed? (Regions are based on US Census)

1. Northeast (Connecticut, Maine, Massachusetts, New Hampshire, New Jersey, New York, Pennsylvania, Rhode Island, Vermont)

2. Midwest (Illinois, Indiana, Iowa, Kansas, Michigan, Minnesota, Missouri, Nebraska, North Dakota, Ohio, South Dakota, Wisconsin)

3. South (Alabama, Arkansas, Delaware, Florida, Georgia, Kentucky, Louisiana, Maryland, Mississippi, North Carolina, Oklahoma, South Carolina, Tennessee, Texas, Virginia, Washington D. C., West Virginia)

4. West (Alaska, Arizona, California, Colorado, Hawaii, Idaho, Montana, Nevada, New Mexico, Oregon, Utah, Washington, Wyoming)

5. Other US Territory or International location

\section{Military Involvement Questions}

1. How many years have you served/did you serve in the Army?

Please enter the duration of service in years and months: 
2. Please check the box that best describes your current military status with the U.S. Army: Active Duty Soldier

Reserve Service Member

National Guard

Veteran

3. Which best describes your current/former status (for Veterans) in the United States Army?

(Check all that apply)

Enlisted

Officer

Warrant Officer

4. Have you ever been deployed?

Yes

No

5. Have you ever received formal resilience training as part of your military service?

Yes

No

6. (If yes), did you find the resilience training useful?

Yes

No

\section{Physical Activity}

The next section asks about various "levels" of physical activity (vigorous, moderate, light) while at your job, while at home, and during your leisure/free time. Please answer each question thinking first about summertime, then about wintertime. (If the question does not apply to you, for example, because you do not have a paid job or are retired, please circle 6 for "Never".)

1. How often do you engage in vigorous physical activity that causes your heart to beat so rapidly that you can feel it in our chest and you perform the activity long enough to work up a good sweat and are breathing heavily? (Examples: competitive sports like running, vigorous swimming, or high intensity aerobics; digging in the garden, or lifting heavy objects).

\begin{tabular}{|c|c|c|c|c|c|c|}
\hline & $\begin{array}{l}\text { Several } \\
\text { Times a } \\
\text { week }\end{array}$ & $\begin{array}{c}\text { Once a } \\
\text { week }\end{array}$ & $\begin{array}{l}\text { Several } \\
\text { times a } \\
\text { month }\end{array}$ & $\begin{array}{c}\text { Once a } \\
\text { month }\end{array}$ & $\begin{array}{c}\text { Less than } \\
\text { once a } \\
\text { month }\end{array}$ & Never \\
\hline \multicolumn{7}{|l|}{ While at your paid job... } \\
\hline a. During the Summer? & 1 & 2 & 3 & 4 & 5 & 6 \\
\hline b. During the Winter? & 1 & 2 & 3 & 4 & 5 & 6 \\
\hline \multicolumn{7}{|c|}{ While performing chores in and around your home... } \\
\hline a. During the Summer? & 1 & 2 & 3 & 4 & 5 & 6 \\
\hline b. During the Winter? & 1 & 2 & 3 & 4 & 5 & 6 \\
\hline
\end{tabular}


a. During the Summer?

b. During the Winter?

$\begin{array}{ll}1 & 2 \\ 1 & 2\end{array}$

3

4

5

6

$\begin{array}{lllll}2 & 3 & 4 & 5 & 6\end{array}$

How often do you engage in moderate physical activity, that is not physically exhausting, but it causes your heart rate to increase slightly and you typically work up a sweat? (Examples: leisurely sports like light tennis, slow or light swimming, low impact aerobics, or golfing without a power cart; brisk walking, mowing the lawn with a walking lawnmower)

\begin{tabular}{|c|c|c|c|c|c|c|}
\hline & $\begin{array}{l}\text { Several } \\
\text { Times a } \\
\text { week }\end{array}$ & $\begin{array}{c}\text { Once a } \\
\text { week }\end{array}$ & $\begin{array}{l}\text { Several } \\
\text { times a } \\
\text { month }\end{array}$ & $\begin{array}{l}\text { Once a } \\
\text { month }\end{array}$ & $\begin{array}{c}\text { Less than } \\
\text { once a } \\
\text { month }\end{array}$ & Never \\
\hline \multicolumn{7}{|l|}{ While at your paid job... } \\
\hline a. During the Summer? & 1 & 2 & 3 & 4 & 5 & 6 \\
\hline b. During the Winter? & 1 & 2 & 3 & 4 & 5 & 6 \\
\hline \multicolumn{7}{|c|}{ While performing chores in and around your home... } \\
\hline a. During the Summer? & 1 & 2 & 3 & 4 & 5 & 6 \\
\hline b. During the Winter? & 1 & 2 & 3 & 4 & 5 & 6 \\
\hline \multicolumn{7}{|c|}{ During your leisure or free time... } \\
\hline a. During the Summer? & 1 & 2 & 3 & 4 & 5 & 6 \\
\hline b. During the Winter? & 1 & 2 & 3 & 4 & 5 & 6 \\
\hline
\end{tabular}

How often do you engage in light physical activity that requires little physical effort? (Examples: light house keeping like dusting or laundry; bowling, archery, easy walking, golfing with a power cart or fishing)

$\begin{array}{lcllll}\begin{array}{l}\text { Several } \\ \text { Times a } \\ \text { week }\end{array} & \begin{array}{c}\text { Once a } \\ \text { week }\end{array} & \begin{array}{l}\text { Several } \\ \text { times a } \\ \text { month }\end{array} & \begin{array}{c}\text { Once a } \\ \text { month }\end{array} & \begin{array}{c}\text { Less than } \\ \text { once a } \\ \text { month }\end{array} & \text { Never } \\ & & & & & \end{array}$

While at your paid job...

a. During the Summer?

b. During the Winter?

1

While performing chores in and around your home...

\begin{tabular}{|c|c|c|c|c|c|c|}
\hline a. During the Summer? & 1 & 2 & 3 & 4 & 5 & 6 \\
\hline b. During the Winter? & 1 & 2 & 3 & 4 & 5 & 6 \\
\hline \multicolumn{7}{|c|}{ During your leisure or free time... } \\
\hline a. During the Summer? & 1 & 2 & 3 & 4 & 5 & 6 \\
\hline b. During the Winter? & 1 & 2 & 3 & 4 & 5 & 6 \\
\hline
\end{tabular}

\section{Multidimensional Scale of Perceived Social Support}

(Zimet, Dahlem, Zimet \& Farley, 1988)

Instructions: We are interested in how you feel about the following statements. Read each statement carefully. Indicate how you feel about each statement.

Circle the " 1 " if you Very Strongly Disagree

Circle the "2" if you Strongly Disagree 
Circle the " 3 " if you Mildly Disagree

Circle the "4" if you are Neutral

Circle the " 5 " if you Mildly Agree

Circle the "6" if you Strongly Agree

Circle the "7" if you Very Strongly Agree

1. There is a special person who is around when I am in need.

2. There is a special person with whom I can share my joys and sorrows.

3. My family really tries to help me.

4. I get the emotional help and support I need from my family.

5. I have a special person who is a real source of comfort to me.

6. My friends really try to help me.

7. I can count on my friends when things go wrong.

8. I can talk about my problems with my family.

9. I have friends with whom I can share my joys and sorrows.

10. There is a special person in my life who cares about my feelings.

11. My family is willing to help me make decisions.

12. I can talk about my problems with my friends.

*Are there other forms of social support you receive? If so, please list them here:

\section{Coping Self-Efficacy Scale}

When things aren't going well for you, or when you're having problems, how confident or certain are you that you can do the following:

Cannot do at all

$\begin{array}{lllllllllll}\mathbf{0} & \mathbf{1} & \mathbf{2} & \mathbf{3} & \mathbf{4} & \mathbf{5} & \mathbf{6} & \mathbf{7} & \mathbf{8} & \mathbf{9} & \mathbf{1 0}\end{array}$

For each of the following items, write a number from 0 - 10, using the scale above. When things aren't going well for you, how confident are you that you can:

1. Keep from getting down in the dumps.

2. Talk positively to yourself.

3. Sort out what can be changed, and what cannot be changed.

4. Get emotional support from friends and family.

5. Find solutions to your most difficult problems.

6. Break an unsettling problem down into smaller parts.

7. Leave options open when things get stressful.

8. Make a plan of action and follow it when confronted with a problem.

9. Develop new hobbies or recreations.

10. Take your mind off unpleasant thoughts.

11. Look for something good in a negative situation.

12. Keep from getting sad.

13. See things from the other person's point of view during a heated argument. 
14. Try other solutions to your problems if your first solutions don't work.

15. Stop yourself from being upset by unpleasant thoughts.

16. Make new friends.

17. Get friends to help you with the things you need.

18. Do something positive for yourself when you get discouraged.

19. Make unpleasant thoughts go away.

20. Think about one part of the problem at a time.

21. Visualize a pleasant activity or place.

22. Keep yourself from feeling lonely.

23. Pray or meditate.

24. Get emotional support from community organizations or resources.

25. Stand your ground and fight for what you want.

26. Resist the impulse to act hastily when under pressure.

\section{Revised Life Orientation Test (LOT-R)}

Instructions: Please answer the following questions about yourself by indicating the extent of your agreement using the following scale:

$[0]=$ strongly disagree

[1] $=$ disagree

$[2]=$ neutral

$[3]=$ agree

[4] = strongly agree

Be as honest as you can throughout, and try not to let your responses to one question influence your response to other questions. There are no right or wrong answers.

1. In uncertain times, I usually expect the best.

2. It's easy for me to relax.

3. If something can go wrong for me, it will.

4. I'm always optimistic about my future.

5. I enjoy my friends a lot.

6. It's important for me to keep busy.

7. I hardly ever expect things to go my way.

8. I don't get upset too easily.

9. I rarely count on good things happening to me. 
10. Overall, I expect more good things to happen to me than bad.

\section{Connor-Davidson Resilience Scale 10 (CD-RISC-10)}

For each item, please mark an " $x$ " in the box below that best indicates how much you agree with the following statements as they apply to you over the last month. If a particular situation has not occurred recently, answer according to how you think you would have felt. not true rarely sometimes often truly nearly at all (0) true (1) true (2) true (3) all the time (4)

1. I am able to adapt when changes occur.

2. I can deal with whatever comes my way.

3. I try to see the humorous side of things when I am faced with problems.

4. Having to cope with stress can make me stronger.

5. I tend to bounce back after illness, injury, or other hardships.

6. I believe I can achieve my goals, even if there are obstacles.

7. Under pressure, I stay focused and think clearly.

8. I am not easily discouraged by failure.

9. I think of myself as a strong person when dealing with life's challenges and difficulties.

10. I am able to handle unpleasant or painful feelings like sadness, fear, and anger. 


\section{Appendix C:}

Resource Page for All Participants

\section{Resources for Veterans and Active Duty Service Members}

\section{Military One Source}

Central hub and go-to place for the military community, including:

-Access to confidential counseling, financial and legal support

-Health and wellness service providers

-Deployment and transition resources

-Live chat feature

http://www.militaryonesource.mil 


\section{Operation We Are Here}

Resources for the military community and military supporters including:

-Educational materials and coping resources for PTSD

-links to dozens of other services (housing, employment, stress management)

http://www.operationwearehere.com/PTSD.html

\section{Team Red, White and Blue}

Connects Veterans to their community through physical and social activity

-Locally based free group exercise classes (Yoga, Crossfit, etc), Veteran athletic camps, and group flag runs

http://www.teamrwb.org

\section{Free Mental Health Smart Phone Apps for Veterans}

-Offering free apps to help with:

-Stress, cope with PTSD, gain access to a counselor or therapist, quit smoking, improve sleep, increase positive thinking, work on concussion symptoms, lose weight, track emotional states and triggers, and more.

http://gov.texas.gov/files/disabilities/Vets_SmartphoneApps.pdf

\section{General Sources for Relaxation, Anxiety Management, and Stress Reduction Guided} Exercises, Worksheets

http://www.innerhealthstudio.com

http://www.calmclinic.com/anxiety/treatment/relaxation

\section{Veterans Crisis Line}

1-800-273-8255 Press 1

https://www.veteranscrisisline.net/ForVeterans.aspx

\section{Crisis Text Line}

Counselors on call 24/7, average response time two minutes 471-471

Physical and Psychology Benefits of Physical Activity

http://www.cdc.gov/physicalactivity/basics/pa-health/ 
Appendix D:

Letters of Support 


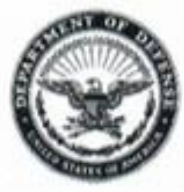

\author{
DEPARTMENT OF THE ARMY \\ RESERVE OFFICERS' TRAINING CORPS (ROTC) \\ WEST VIRGINIA UNIVERSITY \\ PO BOX 6767 \\ MORGANTOWN, WN 26506.6767
}

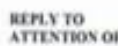

ATCC-DDW-VWV

18 April 2015

MEMORANDUM FOR RECORD

SUBJECT: Survey Personnel

1. I will be able to help Anna Jaeschke in getting her survey to at least 35-50 active duty US Army personnel who will be able to provide her with the numbers of personnel required to support her data analysis for her survey on predictors of resilience.

2. Me being an active duty officer preparing to take command of an battalion of more than 800 personnel as well as having a large group of peers who are on active duty $I$ am more than confident that I can provide her with enough personnel to take the survey to help with her data analysis.

3. If you have any questions or concerns please contact me at steven.m.clark30.milamail.mil or steven.m.clark@outlook.com. I can also be reached on my personal cell phone at 760-887-7424.

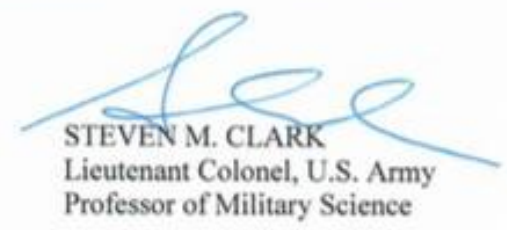


BAE Systems

8201 Greensboro Drive

Suite 1200

McLean, VA 22102

www.baesystems.com

To Whom it May Concern,

I am willing to help Anna-Marie Jaeschke collect data for her dissertation by sending her survey out to peers, friends, colleagues, or other individuals I know who fit the inclusion criteria for her research. I have been informed that her project is on psychosocial predictors of resilience in the military.

I understand that signing this letter is not a binding contract, obligation, or promise. I understand that any active duty service member (including reserves and National Guard) and any veteran can participate in the 15-minute online survey. I am aware that the survey is anonymous and confidential and the researchers will have no identifying information of who has completed the survey.

I know I can send the survey link, (after approval from Institutional Review Board and her committee) via email, social media, or other electronic methods. I am aware that I will receive no financial incentive or reward for helping with this research project and am doing this to further research on resilience in the military. Finally, I know I can contact Anna-Marie or Peter Giacobbi at any point if I have questions about this research study.

Print Name:

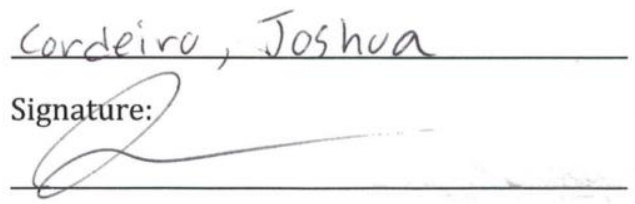

Credentials (Current/Retired Rank or Class):

S6T E-5

Date:

$05-21.16$ 


\section{Appendix E:}

\section{Expanded Literature Review}




\section{Expanded Literature Review}

The following literature review will examine historical roots of resilience, how resilience in defined, theoretical foundations and models of resilience, and how resilience is measured. Conceptually similar constructs such as post-traumatic growth, grit, and mental toughness will be discussed. Resilience will also be explored from a military perspective, including a closer look at resilience training programs. Literature on how resilience is developed within the military and in a general context will also be discussed.

\section{Historical Roots of Resilience}

The study of psychological resilience was fueled by a paradigm shift from a diseasemodel to recognizing and nurturing human strengths (Richardson, 2002). Early resilience research used a developmental approach to understand how some children were able to develop to be fully functional adults despite a difficult childhood (Garmezy, 1975). Noticing that many children did not develop psychopathology despite these adverse circumstances and risk factors lead to the term resilience, or the ability to cope with and bounce back from adversity.

Researchers followed with longitudinal studies examining high-risk children and found that most children developed resilient qualities despite environmental instability (Bernard, 1997; Garmezy, Masten, \& Tellegen, 1984; Rutter, 1979; Werner \& Smith, 1992). Protective qualities or developmental emerged from this research that include both environmental and personal characteristics (Richardson, 2002). Werner and Smith (1992) studied high-risk children after 30 years and found that despite perinatal stress, poverty, parental psychopathology, and daily instability, 72 of the 200 children studied were doing quite well. Protective factors included personal characteristics (being female, robust, adaptable, tolerant, a good communicator, socially responsibly, and self-esteem). Additionally, inside or outside of the family caregiver-quality was 
a valuable buffer to high risk conditions (Werner \& Smith, 1992). Rutter (1979, 1985) found despite stressors and disadvantage that resilient youth had particular qualities including easy temperament, self-mastery, self-efficacy, positive climate at school, planning skills, being female, and a warm relationship with a supportive adult. Garmezy, Masten, and Tellegen (1984) looked at the children of schizophrenic parents and found that most children adapted well as adults and became competent and warm people. The researchers developed a triad of resiliency that included personality disposition, supportive home environment, and external support system(s)(Garmezy et al., 1984; Rutter, 1979, 1985).

While beneficial to identify and recognize resilience, Werner (1995) explored the link between protective factors and successful adaptation in high risk children to see what could inform interventions for at-risk children. Multiple protective factors emerged across studies that contributed to children's ability to overcome adversity, individual characteristics such as socializing behaviors with both adults and peers, problem-solving and communication skills, having a talent or hobby that is valued by others, and a belief that they can initiate actions that have a positive impact on their own life. Environmental protective factors included ties with extended family or the community that reinforce trust, autonomy, and initiative. Caring neighbors, teachers, elders, youth workers, and peers were powerful influences and reinforced resilient children (Werner, 1993, 1995). Characteristics such as social support, self-belief, and problem solving remain prevalent themes in current resilience literature (Connor \& Davidson, 2003; Hu et al., 2015; J. H. Lee et al., 2013). Finally, in an exhaustive review of the literature, Bernard (1997) found that 50-70\% of children globally labeled as "high-risk" grow up to either meet or exceed expectations of societal indicators such as confidence and caring for others (Bernard, 1997). 
This first wave of resiliency captured a comprehensive list of traits, states, characteristics, and qualities that allow people to recover from adverse circumstances and events. This paradigm shift also helped researchers realize that concepts of self-efficacy or esteem do not exist devoid of contextual variables such as supportive environments (Richardson, 2002). Research on resilient children laid the foundation for a continued shift towards studying more of what positive outcomes are gleaned from stress rather than contributors to stress or trauma in a variety of populations.

The second and third waves of resiliency literature focused on how resilient qualities are acquired through coping with stressors and the third wave explored how motivational forces within people and systems drive self-actualization and harmony between biological, psychological, and spiritual sources of strength (Richardson, 2002). However, the third wave has been criticized by researchers as overstating the role resilience plays in dictating universal outcomes (Windle, 2011; Fletcher and Sarkar, 2013). Richardson (2002) and his colleagues (1990) also developed a linear model describing the process of balance, imbalance, and protective factors and developed the metatheory of resilience which greatly influenced the sport resilience model (Galli and Vealey, 2008) and means of measuring resilience in a variety of populations (Connor \& Davidson, 2003).

The field of positive psychology offered a new perspective and focus on individual strengths and this supported a rapid growth of resilience research in several branches of psychology (Seligman \& Csikszentmihalyi, 2000). Particularly over the past two decades, psychologists' exploration of how people function under demanding circumstances has been examined in business (Riolli \& Savicki, 2003), education (Condly, 2006), communities (Campbell-Sills et al., 2009; Lamond et al., 2008), athletic performance (Galli \& Vealey, 2008), 
and military (Meredith et al., 2011; Reivich et al., 2011a). Across many of these settings the term resilience is difficult to study because it can be relative to the situation and researchers often disagree on a uniform definition (Davydov, Stewart, Ritchie, \& Chaudieu, 2010). These conceptual challenges will now be explored.

\section{Definitions of Resilience}

Complexities are evident in the process of defining resilience (Luthar, Cicchetti, \&

Becker, 2000; Masten, 2007) however two characteristics remain salient across various resilience contexts and ways of defining resilience- the presence of adversity and the positive adaptation as a result (Fletcher \& Sarkar, 2013). Definitions have been comprised in an adapted table below:

Table 4: Adapted Table of Definitions of Resilience from Fletcher \& Sarkar, 2013

Agaibi \& Wilson, 2005, p. 197

"Complex repertoire of behavioural tendencies"

"The ability of adults in otherwise normal circumstances who are exposed to an isolated and potentially highly disruptive event such

Bonanno, 2004, p. 20-21 as the death of a close relation or a violent or life-threatening situation to maintain relatively stable, health levels of psychological and physical functioning, as well as the capacity for generative experiences and positive emotions"

Connor \& Davidson, 2003, p. "The personal qualities that enables one to thrive in the face of 76 adversity"

Lee \& Cranford, 2008, p. 213 "The capacity of individuals to cope successful with significant change, adversity, or risk"

Leipold \& Greve, 2009, p. 41

"An individual's stability or quick recovery (or even growth) under significant adverse conditions"

Luthar, Cicchetti, \& Becker, "A dynamic process encompassing positive adaptation within the 2000, p. 543 context of significant adversity"

Masten, 2001, p. 228

"A class of phenomena characterized by good outcomes in spite of serious threats to adaptation or development"

Masten, Best, \& Garmezey, p. 426

"The process of, capacity for, or outcome of successful adaptation despite challenging or threatening circumstances"

"Protective factors which modify, ameliorate or alter a person's

Rutter, 1987, p. 316 response to some environmental hazard that predisposes to a maladaptive outcome" 
Resilience has been described as a trait, outcome, and a process. One point of view uses a psychoanalytic approach and describes ego-resilience, or as a personality trait; this trait being fixed and allows one to manage and adapt to situations of trauma or stress (Block \& Block, 1980). This definition fails to take into account the development of resilience as a process in which an individual interacts with sources of adaptation in their environment. Resilience is constructed from the combination of individual traits and external social influences. Another approach sees resilience as a behavioral or functional outcome that one gains from adapting and recovering from adversity (Masten, 2001). Another common definition of resilience is as a dynamic process in which individuals consciously adapt to adverse circumstances and notes the role in which contextual and environmental factors contribute to positive adaptation (J. H. Lee et al., 2013; Masten, 2001). Research most favors the third conceptualization of resilience as a dynamic process.

Windle (2011) provides the most comprehensive definition of resilience culmination from a review and concept analysis of resilience across multiple disciplines. The definition encompasses components present in resilience: significant adversity/risk, existence of assets or resources, and positive adaptation. Fletcher and Sarkar (2013) emphasize the significant adversity and positive adaptation, but Windle (2011) adds the presence of resources or assets piece in the middle as the vehicle for the development of resilience. Based on the synthesis of these three conceptualizations and many proposed definitions, resilience can be described as "the process of effectively negotiating, adapting to, or managing significant sources of stress or trauma. Assets and resources within the individual, their life and environment facilitate this capacity for adaptation and 'bouncing back' in the face of adversity. Across the life course, the experience of resilience will vary" (Windle, 2011, p. 12). 
Several researchers defined resilience or implied it is measured through the absence of PTSD symptomology (Agaibi \& Wilson, 2005; Meredith et al., 2011; Segovia et al., 2012). One study explored resilience following direct exposure to the September $11^{\text {th }}, 2001$ terrorist attack on the World Trade Center in New York City in a sample of residents surveyed six months after the attack (Bonanno et al., 2007). Resilience was initially examined as the absence of PTSD symptoms, but further analyses examined sociocontextual factors (demographics, availability of resources, and past and current life stressors). Gender emerged as a strong predictor of resilience, with females showing a lower likelihood of resilience.

\section{Models and Theory of Resilience}

Theories can explain or predict processes based on more broad ideas and patterns of concepts in human behavior (Klein \& Zedeck, 2004). In the past few decades, several theories of resilience have been proposed across multiple realms including nursing (Polk, 1997) family adjustment (Patterson, 2002) trauma studies (Agaibi \& Wilson, 2005) community youth (Brennan, 2008), military families (Palmer, 2008), medical students (Dunn, Iglewicz, \& Moutier, 2008) and sport performance (Fletcher \& Sarkar, 2012; Galli \& Vealey, 2008) Most of these theories describe resilience as a dynamic process that incorporates a range of factors. Variation lies in how the theories emphasize factors such as personality, temperament, social support, and coping.

Only the metatheory of resilience (Richardson, 2002) has been touted as a generic theory of resilience that applies across disciplines and has been cited frequently in the literature (Campbell-Sills et al., 2006; Connor \& Davidson, 2003; Fletcher \& Sarkar, 2013; Galli \& Vealey, 2008; Sinclair \& Wallston, 2004; Windle, 2011). However, this theory is not without its flaws and criticism. The view of resilience as a developing process fueled the creation of a 
metatheory of resilience centered on postmodern thinking (Richardson, 2002). The theory dictates that people have the opportunity to consciously or unconsciously choose reactions to life's disruptions and resilience occurs through reintegration. Reintegration is the actual coping process that occurs following the disruption that contributes to self-understanding, growth, knowledge and stronger resilient qualities. While similarities are drawn between this theory and resilience research emphasizing adversity (disruption), and adaptation (reintegration), Richardson (2002) has been heavily criticized for being too linear, and having multiple conceptual flaws with a lack of empirical examination of their explanatory potential (Fletcher \& Sarkar, 2012, 2013)

Theoretical foundations of resilience have also emerged from the stress and coping literature. Social stress theory offers a distinction between stress associated with the consequences of social order or social organizations from stressful antecedents of a psychological disorder such as PTSD (Aneshensel, 1992). Drawing parallels to disagreements in research defining resilience as either protective factors or the absence of psychopathology. In this theory, self-efficacy is also recognized as a mediator between social position and stress.

Another approach is the cognitive motivational relational theory of stress, coping, and adaptation, which views stress as a person-environment relationship perceived as taxing or exceeding one's available resources (Lazarus \& Folkman, 1984). In situations of stress, this theory persists that one will conduct a primary appraisal, or evaluate the potential of the situation and impact or interference with personal objectives. Primary appraisals are distinguished as harm/loss, threat, challenge, or benign. The key to resilience lies in the challenge appraisalwhich offers an opportunity for mastery or personal growth. A benign appraisal leads to no further appraisal or action. These appraisals are linked to factors related to resilience including 
beliefs about control and goal commitment. The secondary appraisal involves appraising control over the situation and employing coping resources.

A final theory associated with resilience is the Broaden-and-Build theory of positive emotions (Fredrickson, 2001, 2004). This theory is rooted in the strong positive relationship between resilience and positive affect. Positive affect has been associated with improvements in individual's ability to bounce back physiologically and psychologically from stressful life experiences (Campbell-Sills et al., 2006; Tugade \& Fredrickson, 2004). The broaden-and-build theory of positive emotions hypothesizes that positive emotions contribute to resilience through broadening a method of flexible thinking, or "thought action repertoires" that become available to someone under stress. Flexible thinking can lead to more expansive options of action and can increase personal resources available to an individual during times of adversity. Additionally, this theory draws on extraversion in the five-factor personality trait model and persists that extraverted people are more likely to have strong support network systems which can be a powerful protective factor when encountering stress (Campbell-Sills et al., 2006; Fredrickson, 2001; Rutter, 1985).

The present study most connects with the cognitive motivational relational theory of stress, coping, and adaptation because although it did not necessarily guide the selection of the variables, the theory describes a primary appraisal and then behavior based on personal characteristics. An appraisal of one's available resources to handle a challenging situation is similar to the process of coping self-efficacy. Additionally, optimism can be described as a personal characteristic that affects one's viewpoint of their world and glean meaning from generally positive outcomes. The conceptualization of resilience as a dynamic process at the intersection of environmental and situational characteristics presents challenges in measurement 
of resilience, however several researchers have developed empirically based instruments to assess for one's ability to bounce back, utilize support systems, and access beneficial internal characteristics.

\section{Measurement of Resilience}

The desire to understand how resilience is relevant to treatment outcomes of clinical conditions such as anxiety, depression, and PTSD sparked interest in developing a means to measure resilience and understand correlates of this construct (Connor \& Davidson, 2003). Coinciding with complexities in defining resilience, researchers are encountering challenges in how to measure resilience in a psychometrically-sound manner (Windle, Bennett, \& Noyes, 2011). Windle, Bennett, and Noyes (2011) conducted a methodological review of resilience measures and found that the Connor-Davidson Resilience Scale, Brief Resilience Scale, and the Resilience Scale for Adults presented the best psychometric ratings. The researchers used a criterion for quality assessment that assessed each scale's: content validity, internal consistency, criterion validity, construct validity, agreement, reliability, responsiveness, floor and ceiling effects, and interpretability. It was noted that the CD-RISC could have benefited from additional items encompassing resilience and stronger theoretical clarity (Windle et al., 2011).

The Connor-Davidson Resilience Scale (CD-RISC) was developed using a combination of research on hardiness (Kobasa, 1979); action orientation, strong self-efficacy, adaptability when coping with change, problem solving skills, past success, and humor (Rutter, 1985); patience and tolerance of negative affect (Lyons, 1991), and anecdotal interactions with optimism and faith from Sir Edward Shackleton's heroic expeditions in the 1912 Antarctic expedition (Alexander, 1998). This measure of resilience has been used extensively with both athlete and non-athlete populations. The researchers developed this measure in response to 
continued research on PTSD, instead of continuous measurement of risk factors, Connor and Davidson (2003) aimed to identify protective factors and be applicable both within and outside of clinical settings.

Since the inception of the 25-item CD-RISC in 2003, it has been translated into several languages and used in a varied of populations including survivors of trauma, large community samples, patients in treatment for PTSD, children, elders, university students, nurses, military personnel, athletes, and missionaries (Davidson \& Connor, 2015). Relationships between CDRISC score and age, ethnicity, marital status, and gender were reported as inconsistent across several studies. The CD-RISC is increasingly used when measuring resilience to identify protective factors as opposed to risk factors, as some research to measure resilience describes it as the absence of PTSD or depressive symptoms (Bonanno et al., 2007; Segovia et al., 2012). The CD-RISC has been used in several studies to describe resilience of military personnel (Green et al., 2014; Hourani et al., 2012; Johnson et al., 2011; Maguen et al., 2008).

\section{Constructs Related to Resilience}

Despite an increase in research on resilience, it remains a challenging concept to define and conceptualize due to its dynamic nature. A challenge in the resilience literature is distinguishing it from other constructs such as post-traumatic growth, hardiness, grit, coping, and mental toughness. All of these concepts identify specific attributes that may allow people to better manage adversity but they are not synonymous (Tedeschi \& Calhoun, 2004). Each construct will be explored briefly below and distinctions are drawn between each and resilience to hopefully offer clarity about resilience.

Post-traumatic growth is defined as "the experience of positive chance that occurs as a result of the struggle with highly challenging life crises" (Tedeschi \& Calhoun, 2004, p 1-2). 
The key with this term is "growth," while resilience is characterized by the continued living or rebound to an original state following adversity: PTG emphasizes a transformation or distinct change in functioning from prior to the adverse circumstance (Tedeschi \& Calhoun, 2004). The emphasis is not on the process of adaptation or recovery, but rather in the transformative growth as a result of the trauma. Resilience has been coined as the ability to "bounce back" while posttraumatic growth refers to the process of "bounding forward." Some definitions of resilience mention growth but most definitions emphasize the ability to overcome and thrive despite adversity. Perhaps in situations of trauma, resilience is the initial response that enables the ability to cope, while PTG is the later process built on the initial resilience response.

Hardiness is described as a personality trait that uses commitment, control, and challenge in response to stress (George A. Bonanno, 2004; Kobasa, 1979). Hardiness means commitment toward finding meaningful purpose in the situation, believe that one can control the surroundings and outcome of events, and the belief that the challenge contributes to learning and growth. Hardiness appears to differentiate from resilience in two ways, firstly in the characterization of hardiness as a personality trait, while resilience has been described as a dynamic process. Secondly, the research more thoroughly documents what contributes to one's resilience (optimism, social support, faith, etc.) while the literature on hardiness focuses more on outcomes that result when hardy people encounter adversity (e.g. problem-solving, lower stress, opportunities for growth) (Maddi, 2005). In that, post-traumatic growth and hardiness could be similar with the emphasis on positive outcomes rather than returning to an original state. The main distinction between the two is that hardiness emphasizes personality traits that are relatively fixed and stable while PTG views resilience as a more dynamic and changing process as individuals grow and adapt. 
Grit is a relatively new concept derived from research in positive psychology and is defined as a trait-level characteristic of passion directed towards long-term goals and perseverance towards those and other pursuits (Duckworth, Peterson, Matthews, \& Kelly, 2007). In addition to hardiness, grit is also focused more on relentless stubbornness and persistency to achieve a goal, with less emphasis on the adversity, barriers, or rewards associated with the goal. Beyond the ability to bounce back or recover in the face of failure, the researchers emphasize that grit is also having intense commitment and loyalty to a pursuit over a long period of time (Perkins-Gough, 2013).

The founders of the term grit developed a Short Grit Scale which included questions on consistency of interest and perseverance of effort (Duckworth \& Quinn, 2009). The measure includes two questions which mention overcoming setbacks: "Setbacks don't discourage me" and "I have overcome setbacks to conquer an important challenge." The inclusion of such questions can create confusion in trying to distinguish these constructs. However, grit is a trait that allows one to persist and remain consistently focused, while resilience is a process in which someone may be persistent and focused while they overcome adversity in pursuit of a goal. Grit can be a contributing factor to resilience, i.e. grittier people could be more resilient, but they remain distinctive in their conceptualization of trait versus process.

Additionally, grit has been studied extensively with those pursuing academic-related goals (spelling competitions, novice teacher retention, and admission into Ivy League Institutions) without taking into account adverse circumstances that could have contributed or hindered goal attainment (Duckworth, Kirby, Tsukayama, Berstein, \& Ericsson, 2011; EskreisWinkler, Shulman, Beal, \& Duckworth, 2014; Robertson-Kraft \& Duckworth, 2014). Similar to hardiness, grit is described as a personality trait but both are distinct from the process of 
surviving and thriving in the face of adversity. To review, certain personality traits can contribute to resilience- such as hardiness and grit, and resilience as a process can help someone both rebound and bound forward from trauma, such as in post-traumatic growth.

Resilience has been described as the process by which people adapt, and can often be used interchangeably with coping, one definition of resilience describes as "the process of coping with stressors, adversity, change, or opportunity" (Richardson, 2002, p.308). However, a growing empirical approach distinguishes resilience and coping as conceptually different (Campbell-Sills et al., 2006). In one study, women who drew on more personality resources (perceptions of control, optimism, self-esteem) appraised an upcoming medical procedure as stressful. While women who scored lower on those resilient qualities had appraisals that directed them to use coping strategies to deal with the upcoming procedure (Major, Richards, Cooper, Cozzarelli, \& Zubek, 1998). The process of coping was described more as means to manage environmental demands that were perceived as greater than one's available resources (Lazarus \& Folkman, 1984). Therefore, resilience has an impact on how a situation is appraised but coping is the process following this appraisal wherein someone employs strategies to manage the stressful situation. Resilience could be viewed as a phenomenon defined by the success of the coping process in challenging circumstances (Leipold \& Greve, 2009).

Another approach views coping as a range of strategies employed by an individual to navigate the demands of a situation, with resilience as an adaptive outcome following the management of the adverse circumstance (Folkman \& Moskowitz, 2004). Researchers found that coping styles contributed to resilience, and relationships were significant after controlling for personality traits. An additional interesting finding was the distinction between task and emotion-focused coping. Task-oriented coping had a positive relationship with resilience while 
emotion-oriented coping was associated with low resilience. It was concluded that an active problem-solving form of coping with adversity would promote resilience (Campbell-Sills et al., 2006). In conclusion, both resilience and coping are described as processes rather than traits, resilience influences appraisal while coping is the employment of a response to the appraisal (Fletcher \& Sarkar, 2013).

Mental toughness carries similar contextual difficulties in regards to a consistent definition, means of measurement, and process for its development (Crust, 2007). One factor that could separate the two is that mental toughness has been referred to something that could develop from both positive and negative situations (Jaeschke, Sachs, \& Dieffenbach, 2016), while resilience is unique in that it requires the presence of an adverse event (Windle, 2011). Another suggested approach is that resilience is the dynamic process of bouncing back from adversity while mental toughness is the strength present to allow one to rebound, much like how grit could be present in resiliency and play a role while the cultivation of resilience is the actual process. Resilience could be described as a learned process of coping via rebounding from challenge, while mental toughness is the ability to unexpectedly manage overcome unexpected stressors even without adequate resources (Gonzalez, 2013). Lastly, resilience was listed as a key characteristics of mental toughness along with self-belief, commitment, self-motivation, thriving on challenge, perseverance, and focus (Crust, 2007; Crust \& Azadi, 2010; Gucciardi, Gordon, \& Dimmock, 2008).

It would be remiss to describe resilience, hardiness, coping, grit, and mental toughness as completely unrelated constructs due to their conceptual similarities. A more appropriate description would be that each construct has unique qualities- whether it is a process or trait, 
requires the presence of adversity, or has been researched in a specific context. Clearly, more research is needed to tease out distinctions.

\section{Resilience Research in the Military}

The pursuit of identifying protective factors over exploration of risks became a focus of the military as rates of PTSD have increased (Yehuda, Vermetten, McFarlane, \& Lehrner, 2014). Research has focused both on building the resilience of active duty service members including part time soldiers such as national guard (Griffith \& West, 2013), and Veterans (Hendricks Thomas et al., 2015; Pietrzak et al., 2010; Pietrzak \& Southwick, 2011). The military often focuses on identifying protective factors such as social support and resilience in conjunction with traumatic stress symptoms (Cunningham et al., 2014; Green et al., 2010; Hourani et al., 2012; Pietrzak et al., 2010). In one study, researchers explored the relationship between trauma exposure and resilience and found a significant interaction; higher scores on the resilience measure appeared to be protective among those who had experienced high combat exposure. Resilience was associated with lower suicidality, fewer problems with alcohol, lower severity of depressive symptoms, and overall fewer medical issues and complaints after controlling for age, gender, minority status, PTSD diagnosis, and trauma exposure (Green et al., 2010). Pietrzak and colleagues (2010) also found that resilience mediated the relationship between PTSD, depressive symptoms, and unit support.

Post-deployment social support in conjunction with resilience have shown to be significant predictors of post-deployment adjustment. Results from one study suggest that those with high post-deployment adjustment found meaningful ways to integrate their transition experiences into healthy relationships, social interactions, and stress coping skills (Cunningham et al., 2014). Of note with this study was that the sample were considered generally healthy and 
those who screened positive or probable for PTSD or those at risk for self-harm were excluded. To support these cross-sectional articles, other researchers conducted a longitudinal study of resilience and mental health in Marines that were close to the conclusion of their military service and then measured resilience and mental health an average of 6 months after returning to civilian life (Hourani et al., 2012). Resilience was found to have a greater impact on functional impairment rather than mental health symptoms. Protective factors that were associated with those not meeting screening criteria for mental health problems included higher scores on preseparation resilience (resilience measured before retirement), and perceived social support at follow-up (on average after 6 months of civilian life). Soldiers that scored high in social support at time of retirement were 5.3 times more likely to see improvement in mental health and functional impairment after 6 months of civilian life. This informs the importance of including a social support component in resilience programming for military personnel as they transition into civilian life (Hourani et al., 2012).

\section{Resilience Training Programs in the Military}

Psychological resilience is particularly important to the military to both keep military service members and military leaders psychologically ready for duty and enhance the well-being of both service members and their primary support systems (Meredith et al., 2011). There exist longstanding concerns with perceptions of vulnerability and stigma associated with help-seeking behaviors in military culture. Resilience training programs can offer support and teach coping skills that can buffer the effects of inevitable stressors encompassing military service-particularly multiple deployments. Resilience training is gaining traction in multiple branches of the military (see Meredith et al., 2011 for review). The United States Army has incorporated resilience training into their unit and leadership-level mandatory training under the umbrella of the Army 
Readiness Initiative. Under Army Regulation 350-53, all enlisted soldiers must complete annual training of Comprehensive Soldier and Family Fitness Resilience and Performance Skills (Odierno, 2014).

It is important to distinguish the Master Resilient Training (MRT) program from the standard unit-level resilience training program. The MRT training takes place at the University of Pennsylvania center for positive psychology and is an intense week long training for NonCommissioned Officers (NCOs) to then take the resilience curriculum back to their unit. The program is based on a train the trainer model in which leadership are trained and then bring the resilience curriculum back to their unit. The CSF2 program is designed to help soldiers become stronger physically, socially, spiritually, and in their family relationships. The program emphasizes six core competencies: self-awareness, self-regulation (emotional regulation), optimism, mental agility, strength of character, and connection (Meredith et al., 2011; Reivich et al., 2011a).

In summary, research on resilience is supported by continued exploration of historical context, definitions of resilience based on various study samples, theoretical foundations that help describe resilience, psychometrically-sound means of measuring resilience, and constructs that are similar but can be distinct from resilience. It is clear that more research is warranted in this area, especially as it pertains to applications of resilience training within high stress environments such as the military. 